\title{
Comprehensive assessment of meteorological conditions and airflow connectivity during HCCT-2010
}

\author{
A. Tilgner ${ }^{1}$, L. Schöne ${ }^{1}$, P. Bräuer ${ }^{1}$, D. van Pinxteren ${ }^{1}$, E. Hoffmann ${ }^{1}$, G. Spindler ${ }^{1}$, S. A. Styler ${ }^{1}$, S. Mertes ${ }^{1}$, \\ W. Birmili ${ }^{1}$, R. Otto ${ }^{1}$, M. Merkel $^{1}$, K. Weinhold ${ }^{1}$, A. Wiedensohler ${ }^{1}$, H. Deneke ${ }^{1}$, R. Schrödner ${ }^{1}$, R. Wolke ${ }^{1}$, \\ J. Schneider ${ }^{2}$, W. Haunold ${ }^{3}$, A. Engel ${ }^{3}$, A. Wéber ${ }^{3}$, and H. Herrmann ${ }^{1}$ \\ ${ }^{1}$ Leibniz Institute for Tropospheric Research (TROPOS), Leipzig, Germany \\ ${ }^{2}$ Particle Chemistry Department, Max Planck Institute for Chemistry, Mainz, Germany \\ ${ }^{3}$ Institute for Atmospheric and Environmental Sciences (IAU), Goethe University Frankfurt, Frankfurt, Germany
}

Correspondence to: H. Herrmann (herrmann @ tropos.de)

Received: 11 December 2013 - Published in Atmos. Chem. Phys. Discuss.: 21 January 2014

Revised: 1 July 2014 - Accepted: 7 July 2014 - Published: 5 September 2014

\begin{abstract}
This study presents a comprehensive assessment of the meteorological conditions and atmospheric flow during the Lagrangian-type "Hill Cap Cloud Thuringia 2010" experiment (HCCT-2010), which was performed in September and October 2010 at Mt. Schmücke in the Thuringian Forest, Germany and which used observations at three measurement sites (upwind, in-cloud, and downwind) to study physical and chemical aerosol-cloud interactions. A Lagrangian-type hill cap cloud experiment requires not only suitable cloud conditions but also connected airflow conditions (i.e. representative air masses at the different measurement sites). The primary goal of the present study was to identify time periods during the 6-week duration of the experiment in which these conditions were fulfilled and therefore which are suitable for use in further data examinations. The following topics were studied in detail: (i) the general synoptic weather situations, including the mesoscale flow conditions, (ii) local meteorological conditions and (iii) local flow conditions. The latter were investigated by means of statistical analyses using best-available quasi-inert tracers, $\mathrm{SF}_{6}$ tracer experiments in the experiment area, and regional modelling. This study represents the first application of comprehensive analyses using statistical measures such as the coefficient of divergence (COD) and the crosscorrelation in the context of a Lagrangian-type hill cap cloud experiment. This comprehensive examination of local flow connectivity yielded a total of 14 full-cloud events (FCEs), which are defined as periods during which all connected flow and cloud criteria for a suitable Lagrangian-type ex-
\end{abstract}

periment were fulfilled, and 15 non-cloud events (NCEs), which are defined as periods with connected flow but no cloud at the summit site, and which can be used as reference cases. The overall evaluation of the identified FCEs provides the basis for subsequent investigations of the measured chemical and physical data during HCCT-2010 (see http://www.atmos-chem-phys.net/special_issue287.html).

Results obtained from the statistical flow analyses and regional-scale modelling performed in this study indicate the existence of a strong link between the three measurement sites during the FCEs and NCEs, particularly under conditions of constant southwesterly flow, high wind speeds and slightly stable stratification. COD analyses performed using continuous measurements of ozone and particle $(49 \mathrm{~nm}$ diameter size bin) concentrations at the three sites revealed, particularly for COD values $<0.1$, very consistent time series (i.e. close links between air masses at the different sites). The regional-scale model simulations provided support for the findings of the other flow condition analyses. Cross-correlation analyses revealed typical overflow times of $\sim 15-30 \mathrm{~min}$ between the upwind and downwind valley sites under connected flow conditions. The results described here, together with those obtained from the $\mathrm{SF}_{6}$ tracer experiments performed during the experiment, clearly demonstrate that (a) under appropriate meteorological conditions a Lagrangian-type approach is valid and (b) the connected flow validation procedure developed in this work is suitable for identifying such conditions. Overall, it is anticipated that the methods and tools developed and applied in the present 
study will prove useful in the identification of suitable meteorological and connected airflow conditions during future Lagrangian-type hill cap cloud experiments.

\section{Introduction}

Clouds occupy on average $\sim 15 \%$ of the volume of the lower troposphere (Pruppacher and Jaenicke, 1995) and play a crucial role in the various physical and chemical processes occurring there (Heintzenberg and Charlson, 2009; Möller, 2010; Ravishankara, 1997). Thus, physical and chemical cloud processes influence large-scale environmental issues such as climate change and, by extension, have a variety of societal implications (Boucher et al., 2013). Since both the spatial and temporal occurrence and the altitude of clouds are highly variable, investigations of physical and chemical interactions between gases, aerosol particles and cloud droplets are quite challenging. Consequently, these interactions are much less understood than pure gas-phase processes. Several hill cap cloud experiments conducted in the past - at Kleiner Feldberg, Germany, in 1990 (Wobrock et al., 1994); at Great Dun Fell, United Kingdom, in 1993 and 1995 (Bower et al., 1999; Choularton et al., 1997); at Tenerife, Spain, in 1997 (Bower et al., 2000); and at Mt. Schmücke, Germany, in 2001 and 2002 (Herrmann et al., 2005) - have shown that ground-based Lagrangian-type experiments, where an orographic cloud is used as a natural flow-through reactor, provide a valuable opportunity to study cloud processes in detail.

Ground-based cloud experiments offer the opportunity to characterise the gas phase, the aerosol particle phase, and the cloud droplet phase in much experimental detail before, during and after cloud processing, and thus enable an advanced understanding of chemical cloud effects and interactions. However, the use and quality of Lagrangian-type hill cap cloud field campaigns strongly depends on meteorological conditions: without a connected flow, comparisons of the physical and chemical properties of aerosol upwind and downwind of a cloud are meaningless. For this reason, successful investigation of data sets obtained during these experiments requires as a necessary condition a critical evaluation of meteorological and flow connectivity conditions (see Tilgner et al., 2005; Heinold et al., 2005).

In the present study, so-called "connected flow conditions" are defined as conditions where the incoming flow passes the upwind area and subsequently the mountain ridge before finally reaching the downwind area. It is explicitly noted here that "connected flow conditions" do not necessarily require an air parcel trajectory to connect all three sampling sites, as these sites were designed to measure representative aerosol compositions in the upwind, summit and downwind areas. In general, hill cap cloud experiments make use of the fact that air parcels can be forced to traverse a hill or a mountain ridge and that - under favourable conditions - the terrain-induced lifting cools down the air parcel so that an orographic cloud is formed near the mountain ridge. Under these "natural flow-through reactor" conditions, the cloudinduced changes to the concentrations of both particle- and gas-phase compounds can be characterised by ground-based field measurements conducted upwind, in-cloud and downwind of the mountain ridge.

The connectivity of atmospheric flow across a mid-level mountain ridge can be evaluated using non-dimensional parameters like the Froude and Richardson numbers (see Heinold et al., 2005, and references therein). These parameters can be derived from measurements of the horizontal wind field and the vertical stratification. An essential question is whether the incoming air parcel contains enough kinetic energy (i.e. wind speed) to ascend and pass over the mountain ridge under a given set of vertical thermal conditions. Thus, vertical stratification and wind shear come into play as well. In reality, the evaluation of flow connectivity can be complicated by wind shear and by non-homogeneous terrain, such as a variable crest line and changing surface roughness. For these reasons, other local parameters also need to be used to assess the likelihood of an air parcel passing over a mountain ridge.

The movement of an air parcel across a mountain ridge can also be ascertained using continuously measured tracer species. These tracer species can include, for example, relatively inert gas-phase species, such as ozone $\left(\mathrm{O}_{3}\right)$, and atmospheric aerosol particles that are not expected to be modified by a cloud passage, such as interstitial particles of a certain size. Another method for validation of flow connectivity is provided by dedicated introduced inert tracer experiments, which are typically performed only occasionally during measurement campaigns (see Heinold et al., 2005, and references therein).

In order for equivalent, and thus comparable, air masses to exist at all sites, measurement periods must not be affected by air mass changes (i.e. front passages) or precipitation. For this reason, an assessment of the synoptic and local meteorological conditions must also be included in an evaluation of the overall suitability of a given set of conditions for further investigation of cloud passage experiment data.

The present work intends to perform a comprehensive assessment of meteorological conditions and flow connectivity during the Hill Cap Cloud Thuringia (HCCT-2010) experiment in order to provide evaluated periods with both adequate meteorological conditions and flow connectivity. Since fulfilment of these conditions is a prerequisite for meaningful comparisons of the physical and chemical aerosol properties measured in the upwind (before the cloud interaction), summit (inside the cloud) and downwind (after the cloud interaction) regions, the comprehensive analysis presented here is of major importance both for previously published works and for additional further studies performed using data obtained during HCCT-2010 (e.g. those contained in the HCCT-2010 Special Issue, http://www. 
atmos-chem-phys.net/special_issue287.html). Moreover, the methodology used and applied here is of a wider scientific interest for the design and interpretation of Lagrange-type hill cap cloud experiments.

HCCT-2010 was conducted in September and October 2010 at Mt. Schmücke (937 m a.m.s.1.), which is part of the mountain ridge of the Thuringian Forest (Germany). This location was previously used for the hill cap cloud campaign FEBUKO (Field Investigations of Budgets and Conversions of Particle Phase Organics in Tropospheric Cloud Processes; see Herrmann et al., 2005 for further details), in which the local meteorological conditions and airflow characteristics were studied extensively (Tilgner et al., 2005; Heinold et al., 2005). During FEBUKO, model calculations and tracer experiments showed that the flow between the measurement sites was reasonably well connected during many cloud events.

In preparation for HCCT-2010, we re-evaluated results obtained during the FEBUKO study and also examined more recent meteorological data (2004-2008). In these evaluations, we found that the maximum probability for hill cap clouds to occur in the area occurred during September and October. This run-up analysis showed, for example, that on 5-year average, approximately 10 cloud events occurred per month in each of September and October under suitable wind conditions (i.e. southwesterly (SW) wind direction). From this analysis, it was decided to conduct HCCT-2010 during September and October 2010, as these months provided the highest probability of occurrence of warm orographic clouds in connection with SW flow (i.e. flow traversing the mountain range in perpendicular fashion).

In analogy to the previous studies performed at Mt. Schmücke (see Tilgner et al., 2005; Heinold et al., 2005), the present work examines the synoptic conditions, flow connectivity and other meteorological issues important for the experimental concept of the hill cap cloud experiment HCCT-2010. First, the mesoscale conditions were evaluated, with particular attention paid to the incident flow conditions and the properties of the air masses advected into the HCCT2010 study area. Then, the properties of the local airflow were analysed in detail. In particular, the connectivity of atmospheric flow across the mountain ridge was assessed using meteorological, aerosol and gas-phase parameters measured upwind, on top and downwind of the mountain ridge. The entire measurement period was analysed using statistical measures with respect to the prevalence of the same air mass at all sites, irrespective of wind direction and the presence or absence of an orographic cloud. Classification criteria were then developed concerning two main issues: (i) whether the airflow was likely to be connected between the three observation areas across the mountain ridge and (ii) whether a hill cap cloud was present and therefore likely to have influenced the air parcel travelling across the ridge. All selected reference periods (i.e. full-cloud events, see below) of HCCT2010 are further evaluated with respect to the question of flow connectivity and cloud conditions. Both calculations of non-dimensional flow parameters (e.g. the Froude number, $F r$ ) and simulations performed using the COSMO meteorological forecast model (COnsortium for Small-scale MOdelling, Baldauf et al., 2011; Schättler et al., 2012) were used to characterise the regional flow regime in the mountainous terrain. For several specific periods, the airflow was verified using dedicated tracer experiments, which were performed using the inert gas $\mathrm{SF}_{6}$. In addition, locally measured meteorological and microphysical data, rawinsonde observations, satellite pictures, ceilometer data and calculated backward trajectories were used to identify orographic/non-orographic cloudiness, to detect frontal processes, and to characterise both the air mass advection and the cloud conditions during the selected event periods. Finally, these meteorological and connected flow investigation results were used to comprehensively identify periods, here referred to as full-cloud events (FCEs) and non-cloud events (NCEs), suitable for use in further investigations. Here, FCEs are defined as periods where all predefined connected flow and cloud criteria for a suitable Lagrangian-type experiment were fulfilled (see Sect. 3.2 for details), while NCEs are defined as periods with connected flow conditions but without clouds present at any of the three measurement sites.

\section{Methods and implementation}

\subsection{Measurement site description}

HCCT-2010 was conducted at Mt. Schmücke in Thuringia, Germany, during September and October 2010. The summit of Mt. Schmücke belongs to the mid-height mountain ridge of the Thuringian Forest, which runs northwest to southeast for $\sim 60 \mathrm{~km}$ without any major gaps. Based on results obtained during the FEBUKO experiment (see Heinold et al., 2005), three ground-based measurement sites were established during HCCT-2010: Goldlauter (GL, nominal upwind site), Mt. Schmücke (SM, summit site) and Gehlberg (GB, nominal downwind site) (see Fig. 1). The upwind site Goldlauter $\left(10^{\circ} 45^{\prime} 20^{\prime \prime} \mathrm{E}, 50^{\circ} 38^{\prime} 25^{\prime \prime} \mathrm{N}, 605 \mathrm{~m}\right.$ a.m.s.l.) served as the location for characterisation of air parcels approaching the experimental site under southwestern (SW) flow conditions. The summit site Mt. Schmücke $\left(10^{\circ} 46^{\prime} 15^{\prime \prime} \mathrm{E}\right.$, $50^{\circ} 39^{\prime} 19^{\prime \prime}$ N, 937 ma.m.s.l.), where the German Weather Service (Deutscher Wetterdienst, DWD) and the Federal Environmental Office (Umweltbundesamt, UBA) operate a research station, served as the primary location for analysis of physical and chemical aerosol and cloud droplet parameters. The site is located near the mountain ridge, and Mt. Schmücke itself is in the vicinity of the highest peak of the Thuringian Forest (982 ma.m.s.1.). Finally, the downwind site Gehlberg $\left(10^{\circ} 47^{\prime} 32^{\prime \prime} \mathrm{E}, 50^{\circ} 40^{\prime} 21^{\prime \prime} \mathrm{N}\right.$, $732 \mathrm{~m}$ a.m.s.1.) served as the location for characterisation of 
A)

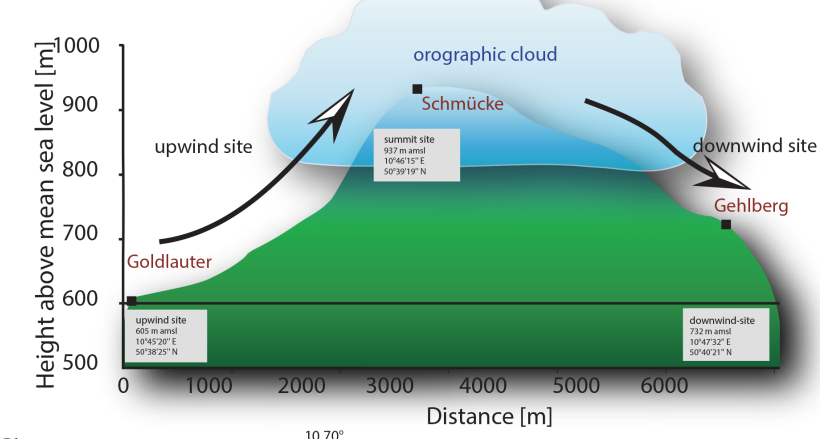

B)

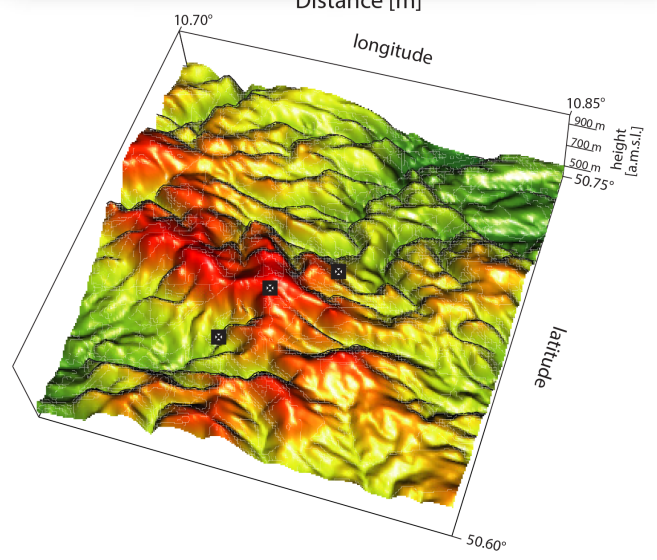

Figure 1. (a) Schematic depiction of the HCCT-2010 measurement area and the three sampling sites, including the upwind site Goldlauter, the summit/in-cloud site Mt. Schmücke and the downwind site Gehlberg. (b) Depiction of the terrain of the measurement area (based on SRTM data (Shuttle Radar Topography Mission) available from the CGIAR-CSI SRTM $90 \mathrm{~m}$ Database v4.1, http://srtm.csi.cgiar.org/; Jarvis et al., 2008).

air masses descending the downwind slope of the Thuringian Forest mountain ridge under appropriate SW flow conditions.

The topography in the measurement area is quite complex (see Fig. 1). The terrain is characterised by a rather narrow valley, wherein the upwind site Goldlauter is located, and two downwind valleys, which begin uphill of the downwind site Gehlberg. Since they permit diverging flow, these valleys can complicate the connected flow conditions. However, previous tracer experiments (Heinold et al., 2005) have shown that, under suitable flow conditions, representative air masses from the upwind area are able to reach the downwind site.

Offline sampling (i.e. experimental measurements with all instruments not running continuously) was performed only under specific suitable conditions. Based on the results obtained during the FEBUKO experiment (Herrmann et al., 2005), the following six criteria were used to determine appropriate time periods for offline sampling during HCCT2010 in the context of a Lagrangian-type hill cap cloud experiment: (i) liquid water content (LWC) of the summit site cloud above $0.1 \mathrm{~g} \mathrm{~m}^{-3}$, (ii) wind direction from the southwest (200-250 sector), (iii) wind speed at Mt. Schmücke of at least $2 \mathrm{~m} \mathrm{~s}^{-1}$ and not exceeding $12 \mathrm{~m} \mathrm{~s}^{-1}$, (iv) no fog at the two valley sites, (v) no precipitation at any site and (vi) air temperature above $0{ }^{\circ} \mathrm{C}$. Further details on these required condition criteria are outlined in Herrmann et al. (2005).

\subsection{Characterisation of the local flow connectivity using coefficient of divergence (COD) of particles in the Aitken $(49 \mathrm{~nm})$ and accumulation mode $(217 \mathrm{~nm})$ range}

During HCCT-2010, particle number size distributions were recorded continuously at all three sites using four identical scanning mobility particle sizers (SMPSs). Selected particle size bins were used in the present study for characterisation of the local flow connectivity. Details regarding the SMPS measurements are given in the Supplement.

In order to investigate spatial variation in selected aerosol size bins between two measurement sites and thus to characterise the degree of similarity between particle data, the coefficient of divergence (COD, sometimes also abbreviated as CD) was used as a statistical measure. This measure has been used in several studies (see e.g. Wongphatarakul et al., 1998; Pinto et al., 2004; Krudysz et al., 2008; Ott et al., 2008; Wang et al., 2011) to determine the relative spatial variability of measured particle mass and constituent concentrations between different sampling sites. In the present study, the COD was used to characterise the temporal similarities between measured particle data at the different HCCT-2010 sites and thus to provide information regarding the airflow over the mountain range. The COD is defined as

$\operatorname{COD}_{a, b}=\sqrt{\frac{1}{n} \sum_{i=1}^{n}\left(\frac{x_{i, a}-x_{i, b}}{x_{i, a}+x_{i, b}}\right)^{2}}$

where $x_{i a}$ and $x_{i b}$ represent the $i$ th aerosol number concentrations measured at sites $a$ and $b$, respectively, and $n$ represents the total number of data points considered in the calculation. In cases where the obtained concentrations at the two sampling sites are very similar, the COD approaches zero. By contrast, in cases where the concentration profiles at two sites differ, the COD approaches unity. It should be noted that the COD represents a measure for comparison of two sites only and therefore cannot be used in the present study to compare all three measurement sites at once. Therefore, for an overall comparison of the three HCCT-2010 sites, the COD of each site combination was calculated; then, all three COD values were compared to a threshold value that indicates similarity between particle data and, by extension, connected flow conditions between the three measurement sites.

The US Environmental Protection Agency (US EPA, 2004) has proposed a COD criterion for the characterisation of the uniformity between aerosol data sets. According to this criterion, COD values larger than 0.2 indicate data set heterogeneity, while COD values below 0.1 indicate data set homogeneity. This criterion is in agreement with other 
studies reported in the literature, which have used a COD of 0.2 as a reference value (see the above-mentioned COD references). In the context of overflow characterisation, this means that lower CODs indicate good flow connectivity conditions, while larger CODs indicate conditions without connected flow (and thus conditions unsuitable for further investigation).

In the present study, a floating $3 \mathrm{~h}$ time span of the measured aerosol number concentrations (i.e. an interval of 3 hours centred around the time point of interest) was used for the calculation of the COD at a given time. Two specific particle diameter bins of the SMPS number size distribution were used for the characterisation of flow connectivity: 49 and $217 \mathrm{~nm}$. The particle number concentration in the $49 \mathrm{~nm}$ diameter bin $\left(N_{49} \mathrm{~nm}\right)$ was selected because this bin represents the upper size range of the aerosol particles that tend to be unaffected by cloud activation. In addition, these particles tend to be substantially less affected by coagulation and diffusion processes than smaller particles. In the case of connected flow, therefore, one would expect low COD values for this parameter. The particle number density in the $217 \mathrm{~nm}$ diameter bin $\left(N_{217} \mathrm{~nm}\right)$ was used to assess the likelihood of in-cloud particle activation, since particles of this size are very likely to be activated in the presence of a cloud, and thus disappear from the interstitial aerosol. Thus, larger COD values for this size bin were used in concert with LWC measurements at the summit site as indicators of fog conditions at the three sites. It should be noted here that the measured $N_{217} \mathrm{~nm}$ values could be slightly affected during the overflow by processes including dry/wet deposition, collision/coagulation, chemical in-cloud mass production and entrainment processes.

The calculated CODs for the different pairs of the three measurement sites and the two aerosol particle size bins are presented in Sect. 3 and given in table form in the Supplement. No time lag between the time series associated with the three measurement sites was applied in these COD calculations. The overall goal of the COD analysis was to identify potentially suitable time periods in an objective and automatic manner. The consideration of predefined assumptions such as a fixed time lag between the different sites contradicts this idea and thus - a priori - it was not possible to include such a time lag. In addition, the magnitude of the time lag varies temporally and, depending on the incoming flow conditions (southwest and northeast wind direction), may be positive or negative. Moreover, the magnitude of the time lags between the sites is typically small compared to the $3 \mathrm{~h}$ time span applied for the COD calculation (see Sect. 3.2.1). Thus, an applied short-term time lag between the time series (according to the transport time between the sites) does not have a huge impact on the obtained results.

\subsection{Characterisation of the local flow connectivity using measured ozone concentrations}

Local measurements of trace gas concentrations can be used to complement particle-based characterisations of the local flow connectivity. A suitable tracer for this purpose must be quasi-inert (i.e. unaffected by chemical decay and deposition during transport on the spatial scale of the experiment) and, in addition, highly variable in both time and space. In previous hill cap cloud campaigns, including the Great Dun Fell experiment (Colvile et al., 1997) and the FEBUKO experiment (Herrmann et al., 2005), ozone was shown to be an appropriate quasi-inert tracer. The reason for this is twofold: first, ozone is only secondarily produced in the troposphere and has no primary direct emission sources; second, since ozone is characterised by low water solubility (Henry's law constant of only $\sim 1.0 \times 10^{-2} \mathrm{M} \mathrm{atm}^{-1}$, see Sander, 1999 , and references therein), it is consumed only ineffectively in acidic continental clouds. Overall, these properties recommend ozone as a suitable quasi-inert tracer for the present connected flow analysis.

During HCCT-2010, ozone concentrations were measured at all three measurement sites with high time resolution using TE49C-TL (up-/downwind sites) and APOA360 (summit site) gas monitors. The measured concentrations are presented in Sect. 3. Previous studies have shown (e.g. Wilson and Birks, 2006) that ozone measurements by UV absorption, i.e. those obtained using a TE49C analyser, can be influenced by potentially large water vapour interferences. In the present studies, the air was not dried before measuring ozone concentrations with the gas monitors. Since the impact on the obtained concentrations should be quite similar for all three sites (similar high relative humidity at all three sites), the temporal behaviour of the measured time series should be not much affected by this artifact. However, for other studies, the influence of water vapour on measured ozone concentrations should be considered.

A connected flow analysis based on measured ozone concentrations comprises a comparison of the concentration time series measured at each site with regard to the concurrency of the ozone concentration levels as well as their temporal behaviour and dependency on the local meteorological conditions. In order to obtain an overall comparison of the concentration time series at the three measurement sites and to investigate the flow connectivity in detail, the CODs for each of the three sites were also calculated using the measured ozone data. Here, low COD values indicate a good concurrency of the ozone concentration time series measured at a given two sites. For a COD calculation at a given time, measured ozone concentrations of a $1 \mathrm{~h}$ time interval were used time-centred around the specific time point. The ozone CODs calculated in this manner are presented in Sect. 3 and given in table form in the Supplement. As was the case for the particle measurements described in the previous section, no time lag 
between the time series associated with the three measurement sites was applied in these COD calculations.

Since the time lag between the measurements, which is mostly correlated with wind speed, was not considered in the present COD analysis and the pattern of the concentration time series are less important for COD analysis, another statistical measure, the cross-correlation value $r_{\text {xcor }}$, was also used to assist in the characterisation of the flow connectivity between the different sites. This measure can be used to compare two time series that cover the same time span: for two time series $x$ and $y$, the cross-correlation value at lag time $d$ is defined by

$r_{\mathrm{xcor}}(d)=\frac{\sum_{i}\left(\left[x_{i}-\bar{x}\right] \cdot\left[y_{i-d}-\bar{y}\right]\right)}{\sqrt{\sum_{i}\left[x_{i}-\bar{x}\right]^{2}} \cdot \sqrt{\sum_{i}\left[y_{i-d}-\bar{y}\right]^{2}}}$.

As can be seen from Eq. (2), the calculated value of $r_{\text {xcor }}$ depends on the magnitude of the time lag between the two time series. The time lag with the highest $r_{\text {xcor }}$ value provides an indication of the air parcel transport time between a set of two stations. High correlations between the measured concentration profiles indicate the existence of connected flow between the three sites and the absence of substantial mixing with surrounding air during air parcel advection. The calculated $r_{\text {xcor }}$ are presented in the Supplement for selected time periods during each of the FCEs identified during the measurement period.

The cross-correlation analysis presented in this section was also performed for the particle data described in the previous section. However, since the temporal resolution of the particle data was coarser than that of the ozone data, and the magnitude of temporal variation in $N_{49} \mathrm{~nm}$ was smaller than that observed for measured ozone concentrations, crosscorrelation analysis of the $N_{49} \mathrm{~nm}$ data did not yield additional useful information. For this reason, the results of this analysis are not considered in the present paper.

\subsection{Characterisation of the flow conditions with non-dimensional parameters}

Non-dimensional flow and stability parameters such as the Froude number $(F r)$ and the Richardson number $(R i)$ can be used to characterise the flow regime in mountainous terrain. Advantageously, such parameters do not require numerically expensive models but rather can be easily derived from locally measured meteorological data. In the literature, the term " $F r$ number" is used to describe a variety of quantities, each of which have dissimilar forms and dynamical significance (see Baines, 1995 for details). In the present paper, the $\mathrm{Fr}$ number is defined as in Pierrehumbert and Wyman (1985):

$F r=\frac{N H}{U}$

in order to characterise whether an air mass will be lifted up and pass over, or be forced to stream around, a mountain bar- rier. As can be seen from Eq. (3), the $F r$ number represents the ratio of the atmospheric potential energy, which is related to the product of the Brunt-Väisälä frequency $N$ and the maximum mountain height $H$, to the kinetic energy of the air flow, which is represented by the characteristic wind speed $U$ of the incoming air flow. The direct proportionality of the $\mathrm{Fr}$ number to the atmospheric stratification represented by the Brunt-Väisälä frequency implies that, under stable stratification conditions of the boundary layer, the Froude number tends to larger values for a given wind velocity. Higher $\mathrm{Fr}$ numbers, which exist under highly stable stratified conditions and/or low wind speeds, reflect the existence of blocking effects.

Model simulations by Pierrehumbert and Wyman (1985) have revealed three critical Froude numbers. For $F r>0.75$, a disturbance propagates upstream with time and results in a decelerated low-level flow, where gravity waves start to amplify. Under these conditions (i.e. under decelerated or blocked upwind low-level flow conditions), stronger downdrafts behind the mountain ridge can occur. These downwind site downdrafts lead to a mixing of low-level air with air from higher altitudes (see Pierrehumbert and Wyman, 1985). For $F r \geq 1.5$, the simulations predict the occurrence of a stagnant area at the low upstream slope. Simulations with even larger $F r$ numbers $(F r>2)$ predict the existence of a fully blocked flow pattern with a stagnant area at the upstream slope. As $\mathrm{Fr}$ continues to increase, this stagnant area extends further in the vertical direction. These theoretical findings have been validated by both laboratory experiments (Baines, 1995) and tracer studies (Bruintjes et al., 1995; Vosper et al., 2002).

The $\mathrm{Fr}$ formulation described above assumes a dry adiabatic lifting of the airflow. However, studies by Jiang (2003) and Colle (2004) have revealed that the critical Fr number (i.e. the value at which the stagnation pattern initiates) is 30 $100 \%$ higher in cases where cloud formation - and associated release of latent heat - occurs. However, since there are many uncertainties associated with the determination of the magnitude of latent heat release from cloud formation, only the "dry" Froude number is used in the present work.

Another dimensionless parameter characterising the level of atmospheric stratification with respect to blocking effects is the Richardson number $(R i)$, which reflects the ratio of the energy extracted by buoyancy forces to the energy gained from wind shear:

$$
R i=\frac{g \partial \theta / \partial z}{\theta(\partial U / \partial z)^{2}} .
$$

Equation (4) includes vertical gradients $\partial / \partial z$ of both the potential temperature $\theta$ and the characteristic wind speed $U$; in this equation, $g$ represents the gravitational acceleration. The sign of the Richardson number reflects the extent of thermal stratification: for $R i>0$, the airflow is statically stable; for $R i<0$, the airflow is statically unstable; for $R i=0$, the airflow is neutral. Under statically stable conditions, airflow 
will become dynamically unstable for $R i$ numbers below a critical value of $\sim 0.25$.

For HCCT-2010, the characteristic non-dimensional flow and stability parameters $\mathrm{Fr}$ and $R i$ were calculated using rawinsonde data from the German Weather Service Station in Meiningen ( $453 \mathrm{~m}$ a.m.s.l., provided by the University of Wyoming, http://weather.uwyo.edu/upperair/ sounding.html), which is located $\sim 30 \mathrm{~km}$ upwind of Mt. Schmücke. Average values and vertical gradients of $U$ and $\theta$ were determined by averaging measurements obtained at the Meiningen station. An effective mountain height of $484 \mathrm{~m}$ was used for the $F r$ and $R i$ calculations, since this height is broadly representative of the mountain ridge level in this region. The $F r$ and $R i$ numbers calculated in this manner are given in Sect. 3 .

Finally, it should be noted that since the calculation of $F r$ and $R i$ numbers is based in part on data taken $\sim 30 \mathrm{~km}$ upwind of Mt. Schmücke, it therefore assumes that both the wind conditions and the thermal stratification were conserved during transport to the measurement site. Since this assumption may not always be valid, the calculated values of $F r$ and $R i$ should be used with caution.

\subsection{Tracer experiments}

To study the local air flow under appropriate meteorological conditions, four tracer experiments (TEs) were performed during the campaign (see Table 1). In these experiments, sulfur hexafluoride $\left(\mathrm{SF}_{6}\right)$ was used as an inert tracer gas and released from a point source (bottle) at the upwind site Goldlauter at a rate of $\sim 3 \mathrm{~L} \mathrm{~min}^{-1}$ for 10-20 min. Air samples were then taken at eight different sites along the expected air flow, including the Mt. Schmücke summit and the downwind Gehlberg sampling sites. The locations of the sampling sites are indicated in Fig. 2 and given with geographical coordinates in Table S1 in the Supplement. Their selection was based on the choice of sites during the previous FEBUKO experiments (Heinold et al., 2005). For consistency, the ID numbers assigned to the sites were kept the same as in Heinold et al. (2005). Air sampling at the sites commenced at the start of the $\mathrm{SF}_{6}$ release and was performed at $5 \mathrm{~min}$ intervals over the course of 1 hour.

Each sample was collected in a $10 \mathrm{~L}$ polyethylene bag, which was exposed to ambient air for $5 \mathrm{~s}$, firmly closed, and transported to the laboratory within $24 \mathrm{~h}$ of sampling. Analysis of $\mathrm{SF}_{6}$ was performed using gas chromatography (GC) with electron capture detection (ECD) using a Siemens Sichromat 1-4 system. A defined amount of air was removed from each bag with a gas-tight syringe and directly injected into the GC. The detection limit of the GC method employed, which is described in detail elsewhere (Strunk et al., 2000), was $0.5 \mathrm{ppt}$ and the precision was $<1 \%$.

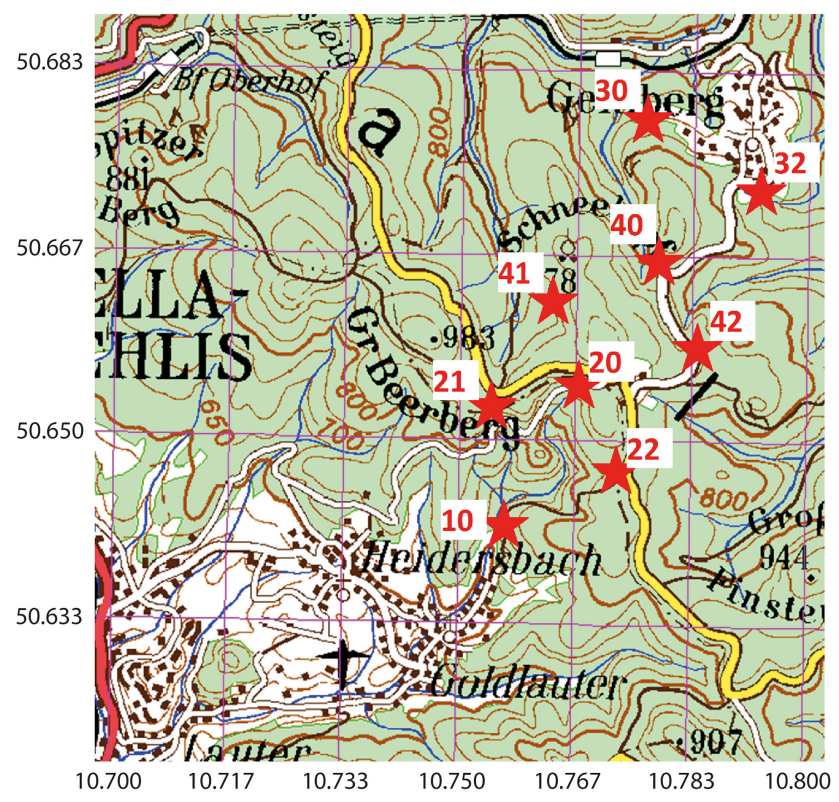

Figure 2. Locations of all tracer experiment sampling sites, including the upwind release site Goldlauter (10), the summit site Mt. Schmücke (20) and the downwind site Gehlberg (30) (map source: Thüringer Landesvermessungsamt).

\subsection{Detailed characterisation of the meteorological and microphysical conditions}

For the examination of the local meteorological conditions during the selected FCE periods, locally measured meteorological and microphysical data, rawinsonde observations, satellite pictures, ceilometer data and calculated backward trajectories were used. Our examination focused on the stability of the incident flow conditions, synoptic front passages, the presence of orographic or non-orographic cloudiness, measured cloud properties such as cloud base height and LWC, vertical thermal stratification and precipitation.

For detection of frontal processes and synoptic-scale advection patterns, surface weather charts with a time resolution of $6 \mathrm{~h}$ and charts of the $850 \mathrm{hPa}$ pressure level were used (see Supplement). In order to identify the air mass origin and to characterise potential source regions of the aerosols measured during a FCE, backward trajectories were calculated with the HYSPLIT model (Draxler and Rolph, 2003; Rolph, 2013). The HYSPLIT model was used in the ensemble mode in order to provide multiple backward trajectories based on a small variation in the applied initial meteorological field. Ensemble trajectory calculations were performed to lower the uncertainties associated with a single trajectory and to investigate the potential variability of the calculated backward trajectories according to variations in the meteorological field. Each calculated ensemble trajectory started from the same location; however, in each case the initial meteorological field was offset by one grid cell in the horizontal and by $250 \mathrm{~m}$ in 


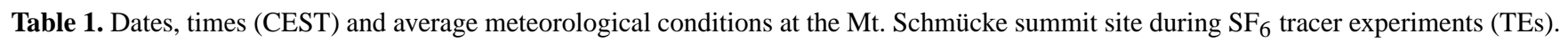

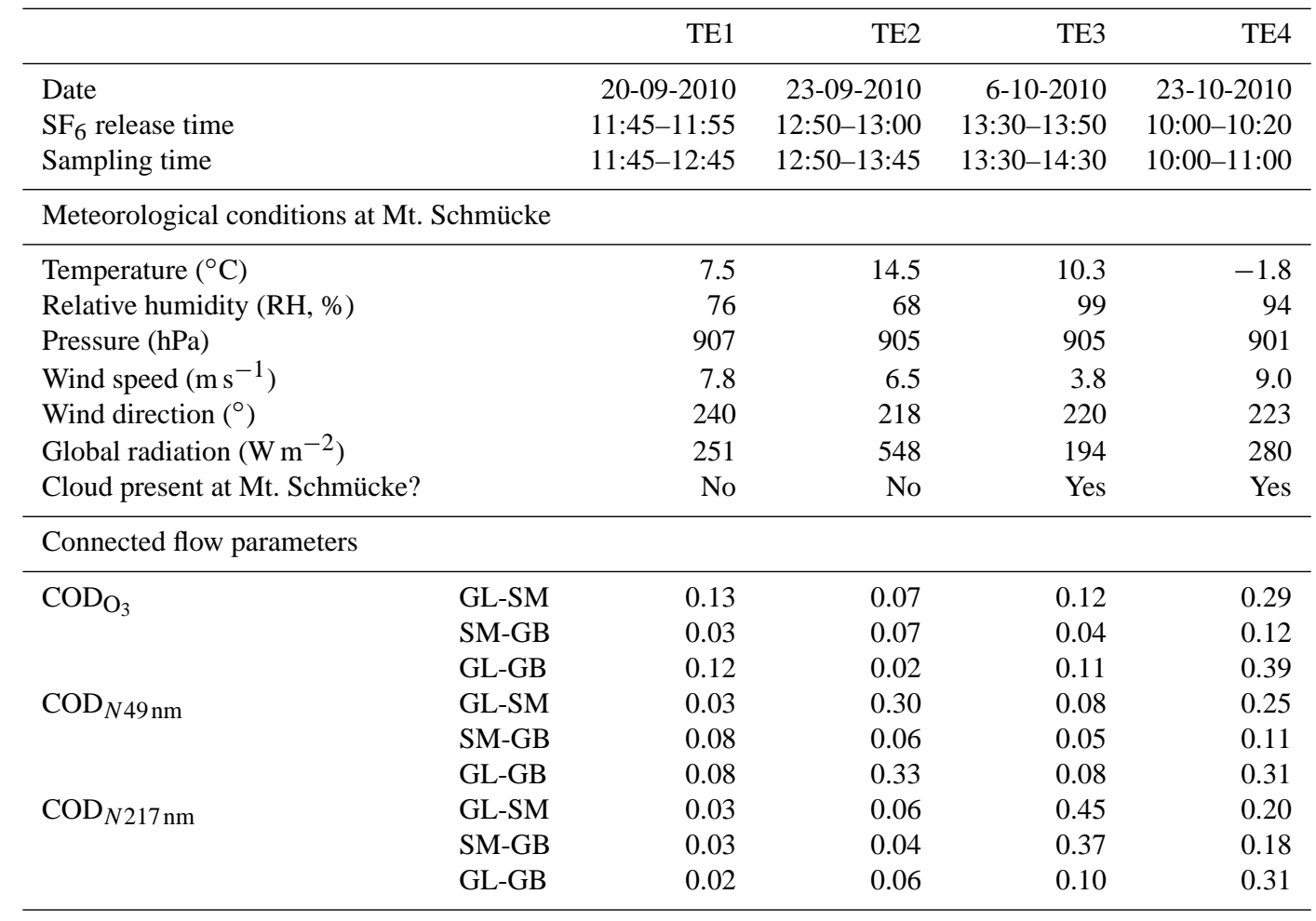

the vertical direction. In this manner, 27 ensemble backward trajectories were calculated (see the Supplement for further details). In order to gain more information regarding aerosol type and origin, the trajectories were also characterised with respect to their residence time over certain land types (urban, agriculture, natural vegetation and bare areas) or water areas during their transport to Mt. Schmücke (see van Pinxteren et al., 2010 for details of the trajectory analysis approach).

For the characterisation of cloud conditions and thermal stratification, satellite pictures and rawinsonde observations were used. For the analyses, both IR and VIS satellite pictures obtained by the geostationary METEOSAT satellite (with $15 \mathrm{~min}$ time resolution) and, if available during the FCEs, polar orbit satellite pictures (obtained from Berliner Wetterkarte e.V., 2010 and DLR) were examined. As discussed in Sect. 2.4, information regarding tropospheric thermal stratification and vertical wind pattern was obtained from analysis of rawinsonde observations from the German Weather Service station Meiningen (source: http: //weather.uwyo.edu/upperair/sounding.html). Vertical wind pattern data in particular were used to characterise vertical thermodynamic conditions for existing clouds, which allowed for the determination of the cloud type present at the measurement site.

Standard meteorological parameters such as temperature, pressure, relative humidity, wind direction, wind speed and precipitation were measured at all three measurement sites using Vantage Pro weather stations. Cloud base height was measured at the upwind site using a ceilometer (Jenoptic Ceilometer CHM 15k-x) and LWC was measured at the summit site using two instruments (FSSP-100 and PVM-100); these data were used to characterise the local microphysical cloud conditions and their temporal homogeneity throughout each FCE. The locally measured data also helped to enable the detection of meteorological front passages and, by extension, possible air mass changes. Overall, the meteorological analysis described in this section allowed for a more sophisticated and comprehensive evaluation of the suitability of selected cloud periods for further analysis using a Lagrangiantype approach.

\subsection{Characterisation of the regional flow conditions using COSMO}

For the model-based investigation of the flow conditions, simulations with the meteorological forecast model COSMO (Baldauf et al., 2011; Schättler et al., 2012) were conducted for the whole measurement period. In brief, COSMO is based on the primitive hydro-thermodynamical equations that describe compressible non-hydrostatic flow in a moist atmosphere. It uses a staggered Arakawa C-grid on a rotated geographical coordinate system and a hybrid terrain-following vertical coordinate. The COSMO model includes the dynamic kernel for the atmosphere and the required parameterisation schemes for numerous 
meteorological processes, boundary conditions and surface exchange relations. COSMO can describe not only the atmospheric flow but also phenomena occurring between the meso- and micro-scales, including near-surface processes, convection, clouds, precipitation, orographic and thermal wind systems. Further details on the model and its implementation can be found elsewhere in the literature (see e.g. Baldauf et al., 2011). In the present study, the COSMO model was applied for a domain spanning between $50^{\circ} \mathrm{N}, 9.5^{\circ} \mathrm{W}$ and $51^{\circ} \mathrm{N}, 11.5^{\circ} \mathrm{W}$ with a horizontal resolution of $\sim 1.4 \mathrm{~km}$ $(100 \times 80$ grid cells $)$. For the investigation of the regionalscale flow conditions, the wind field predicted by COSMO was used. The model output is presented in the Supplement for each of the FCEs identified during the measurement period.

\section{Results and discussion}

\subsection{Characterisation of the general synoptic situations and advected air masses during HCCT-2010}

As shown in Fig. 3, the average synoptic situation during September 2010 was characterised by a weak low-pressure area between Greenland and Iceland as well as a weak highpressure area over Romania, which together resulted in a predominantly westerly flow over Central Europe. The second half of the month in particular was affected by front passages and variable weather conditions.

At the beginning of the field campaign on 14 September at the foreside of a trough over Central Europe (TM), marine air from North Atlantic (mTp) was advected to the measurement site. The day after, the trough moved eastwards and an Atlantic frontal zone reached Central Europe, which led to precipitation with occasional gusty winds. On the backside of the cold front, Greenlandic polar air $(\mathrm{mP})$ was advected to the Mt. Schmücke area; this air mass stayed until 17 September. Trajectory analysis showed that this air mass was mainly influenced by marine and agricultural areas of Great Britain or France. Given the presence of appropriate wind conditions, several (some quite short) offline measurement periods were conducted during this period, despite the presence of precipitation (see Table 2). From 18 September onward, a bridge of high pressure developed over Central Europe. Warmed maritime polar air $(\mathrm{mPt})$ with decreasing oceanic influence approached the Thuringian Forest over the course of the following week (until 23 September), which resulted in moderate winds, mainly from the SW. On 20 and 21 September, the wind direction shifted towards easterly directions without any change in the origin of the air mass. This is in agreement with the trajectory analysis for this period (see the Supplement), which showed that the influence of the continent (i.e. agriculture, natural vegetation) on the air mass increased dramatically with time over the week. On 24 September a transition occurred, and the air mass advection changed towards a more polar air mass. Over the next 3 days (until 28 September), a strengthening low-pressure area over the North Sea advected aged Greenlandic polar air ( $\mathrm{mP})$ to Central Europe. The weather conditions were appropriate for another offline experiment period on 24 and 25 September (see Table 2). The weather situation thereafter was characterised by strong precipitation, which was connected to front passages. The weather situation from 29 September to 3 October was affected by a large high-pressure system over Scandinavia and a low-pressure system over Iceland, which generated temporary precipitation at the corresponding fronts. The air mass was characterised by drier and warmer air (cTp) as compared to previous days and by advection over the continent (France) from the SW. Two offline experiment periods were conducted during this weather situation (see Table 2).

As shown in Table 2, October 2010 experienced five distinct weather periods. No change in the general weather situation was observed for the first 3 days of October as compared to the last period in September. As stated above, two offline experiment periods were conducted during this weather situation. The weather situation from 4 to 8 October was characterised by a high-pressure area over Russia and Poland and areas of low pressure over the Atlantic Ocean. The Mt. Schmücke area in particular was in a zone of weak pressure gradients characterised by warm and humid air advected from the Mediterranean area in the south. The declining pressure gradients caused weak winds first from the SW and later, from 6 October onward, from different directions. One offline experiment period was conducted during this weather situation (see Table 2). The marine-influenced tropical air mass (mTs) caused early morning fog in the Mt. Schmücke area but precipitation only in southern Germany. Frontal systems were blocked in the west and south of Germany by the high-pressure area over Poland and Russia. By 9 October the weather situation changed: the highpressure area over Poland and Russia receded and a new high-pressure area formed over the Norwegian Sea (HNA); in addition, the wind changed to northerly directions, which advected dry continental polar air masses (cP). At this time, under the influence of high pressure, the Mt. Schmücke area experienced early morning fog. Pressure gradients were still weak. By 15 October the general weather situation started to change; from 16 October onward, a trough area over central Europe (TrM) influenced Mt. Schmücke. The trough led to an advection of humid marine polar air masses (mP), which were associated with occasional precipitation over Germany. Two offline experiment periods were conducted during this time period (see Table 2). From 22 October onward, the trough was pushed eastward and westerly conditions (WZ) affected the Mt. Schmücke area, which advected marine air masses $(\mathrm{mPa})$. During this weather situation, two offline cloud experiments were performed (see Table 2). 


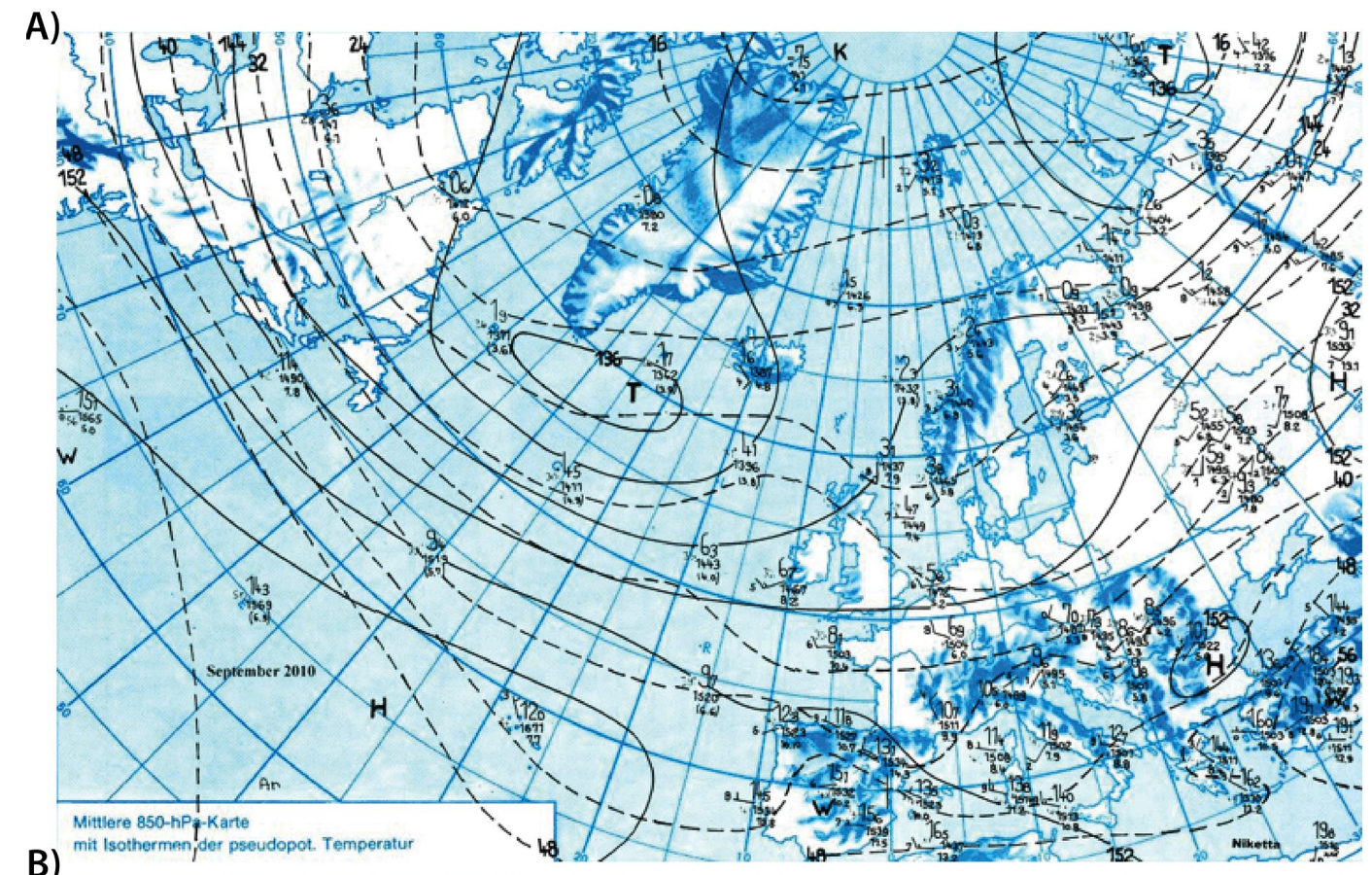

B)

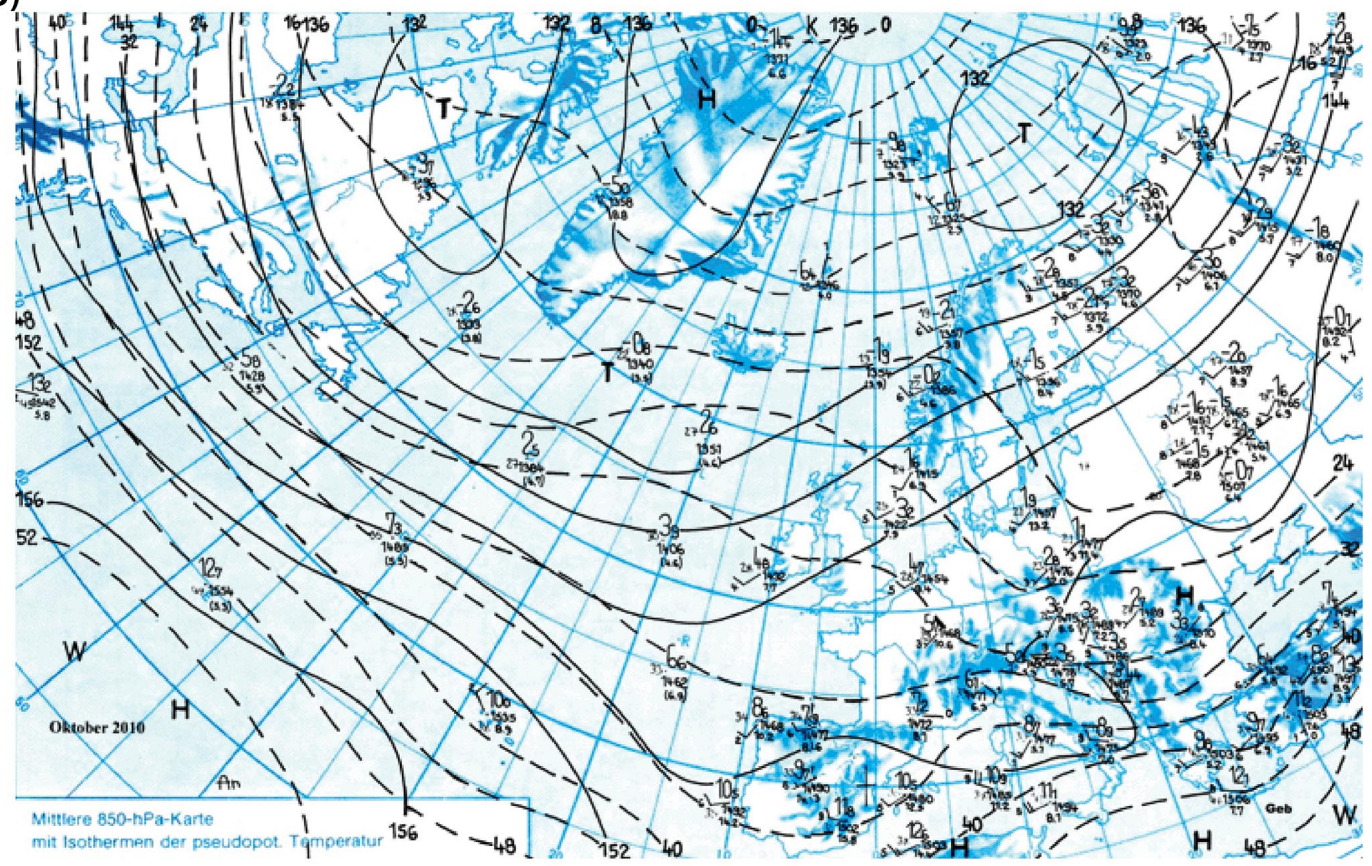

Figure 3. Averaged synoptic situation ( $850 \mathrm{hPa}$ level) over the North Atlantic and Europe in September 2010 (a) and October 2010 (b), including isotherms of the pseudo-potential temperature (source: Berliner Wetterkarte e.V., 2010).

\subsection{Flow characterisation}

\subsubsection{Overflow characterisation with the quasi-inert tracer $\mathrm{O}_{3}$}

As discussed in Sect. 2, measured ozone concentration time series and derived statistical parameters such as the COD and the cross-correlation can be used for the characterisation of the flow connectivity between the different measurement sites and, by extension, for the identification of suitable experimental periods for further investigations. The ozone concentration time series at the three measurement sites and the calculated COD values based on these time series are presented in Fig. 4, together with important meteorological data such as wind speed and direction. Briefly, it is noted that the 
Table 2. Classification of the general weather situations and the associated predominant air masses during the HCCT-2010 field campaign, and the offline-measurement periods (i.e. periods during which both offline and online sampling were conducted).

\begin{tabular}{|c|c|c|c|}
\hline Date & $\begin{array}{l}\text { General weather } \\
\text { situation }^{\mathrm{a}}\end{array}$ & Predominant air mass $b$ & $\begin{array}{l}\text { Offline-measurement } \\
\text { periods (CEST) }\end{array}$ \\
\hline 14 Sep & $\begin{array}{l}\text { Trough Central Europe } \\
\text { (TrM) }\end{array}$ & $\begin{array}{l}\text { Marine air from North } \\
\text { Atlantic } \\
(\mathrm{mPt})\end{array}$ & $\begin{array}{l}14-09-201011: 00 \\
-15-09-201002: 00\end{array}$ \\
\hline 15-17 Sep & $\begin{array}{l}\text { Cyclonic West } \\
\text { (WZ) }\end{array}$ & $\begin{array}{l}\text { Greenlandic polar air } \\
(\mathrm{mP})\end{array}$ & \\
\hline 18-23 Sep & $\begin{array}{l}\text { Bridge over Central } \\
\text { Europe } \\
(\mathrm{BM})\end{array}$ & $\begin{array}{l}\text { Warmed polar air } \\
(\mathrm{mPt})\end{array}$ & \\
\hline $24 \mathrm{Sep}$ & 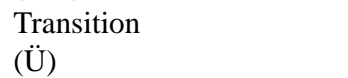 & $\begin{array}{l}\text { Greenlandic polar air } \\
(\mathrm{mP})\end{array}$ & $\begin{array}{l}24-09-201023: 45 \\
-25-09-201001: 45\end{array}$ \\
\hline 25-28 Sep & $\begin{array}{l}\text { Trough Central Europe } \\
\text { (TrM) }\end{array}$ & $\begin{array}{l}\text { Greenlandic polar air } \\
(\mathrm{mP})\end{array}$ & \\
\hline $29 \mathrm{Sep}-03 \mathrm{Oct}$ & $\begin{array}{l}\text { High over Fennoscandia, } \\
\text { cyclonic (HFZ) }\end{array}$ & $\begin{array}{l}\text { Continental tropical air } \\
\text { (cTp) }\end{array}$ & $\begin{array}{l}01-10-201022: 30 \\
-02-10-201005: 30 \\
02-10-201014: 30 \\
-02-10-201020: 00\end{array}$ \\
\hline 04-09 Oct & $\begin{array}{l}\text { Anticyclonic South } \\
\text { (SA) }\end{array}$ & $\begin{array}{l}\text { Mediterranean tropical } \\
\text { air } \\
(\mathrm{mTs})\end{array}$ & $\begin{array}{l}06-10-201012: 15 \\
-07-10-201003: 15\end{array}$ \\
\hline 10-14 Oct & $\begin{array}{l}\text { High over Norwegian Sea } \\
\text { and Iceland, } \\
\text { anticyclonic (HNA) }\end{array}$ & $\begin{array}{l}\text { Continental polar air } \\
(\mathrm{cP})\end{array}$ & \\
\hline 15 Oct & $\begin{array}{l}\text { Transition } \\
\text { (ய̈) }\end{array}$ & $\begin{array}{l}\text { Continental air Central } \\
\text { Europe } \\
(\mathrm{cPt})\end{array}$ & \\
\hline $16-21$ Oct & $\begin{array}{l}\text { Trough Central Europe } \\
\text { (TrM) }\end{array}$ & $\begin{array}{l}\text { Greenlandic polar air } \\
(\mathrm{mP})\end{array}$ & $\begin{array}{l}19-10-201021: 30 \\
-20-10-201003: 30\end{array}$ \\
\hline $22-24$ Oct & $\begin{array}{l}\text { Cyclonic West } \\
\text { (WZ) }\end{array}$ & $\begin{array}{l}\text { Arctic polar air } \\
(\mathrm{mPa})\end{array}$ & $\begin{array}{l}24-10-201001: 30 \\
-24-10-201008: 45 \\
24-10-201009: 15 \\
-24-10-2010 \quad 11: 45\end{array}$ \\
\hline
\end{tabular}

${ }^{a}$ Subjective Hess-Brezowsky classification (Hess and Brezowsky, 1952; revised by Gerstengarbe et al., 1999); ${ }^{\text {b European }}$ air-mass classification (after Scherhag, 1948).

meteorological measurements at the upwind site Goldlauter were performed in a rather narrow valley, i.e. under less suitable wind measurement conditions, and for this reason the wind data obtained at this site should be used with great care only.

Figure 4 shows that the ozone concentrations at the different sites displayed significant spatial and temporal variation - this short-range variability represents the precondition for the statistical analysis. During the measurement period, the ozone concentrations at the three sites varied between several ppb and $\sim 60 \mathrm{ppb}$. As shown in Fig. 4, ozone concentrations measured at the summit and downwind sites generally agreed quite well; by contrast, concentrations measured at the upwind site often deviated from those measured at the other two sites. Strong agreement, and therefore good flow connectivity, between the three ozone concentration time series was mostly present during weather situations with south- western or west-southwestern flow conditions. Strong agreement was also present during weather situations with northeastern winds perpendicular to the mountain ridge. Figure 4 also shows that periods of measurement agreement were associated with higher wind speeds. This congruence reflects the higher kinetic energy of the airflow and, therefore, the higher probability for the air to cross the mountain range. In Fig. 4, the time intervals displaying the highest congruence are highlighted as shaded areas.

Comparison of the measured concentration-time profiles with the associated calculated CODs shows that larger concentration deviations between the time series coincide directly with higher CODs. The COD analysis reveals that higher CODs are typically observed for the upwind site; indeed, the average of the $\mathrm{COD}_{\mathrm{GB}-\mathrm{SM}}(0.11)$ throughout the analysis period is smaller than those of the other two site combinations $\left(\mathrm{COD}_{\mathrm{SM}-\mathrm{GL}}=0.13 ; \mathrm{COD}_{\mathrm{GB}-\mathrm{GL}}=0.16\right)$. 


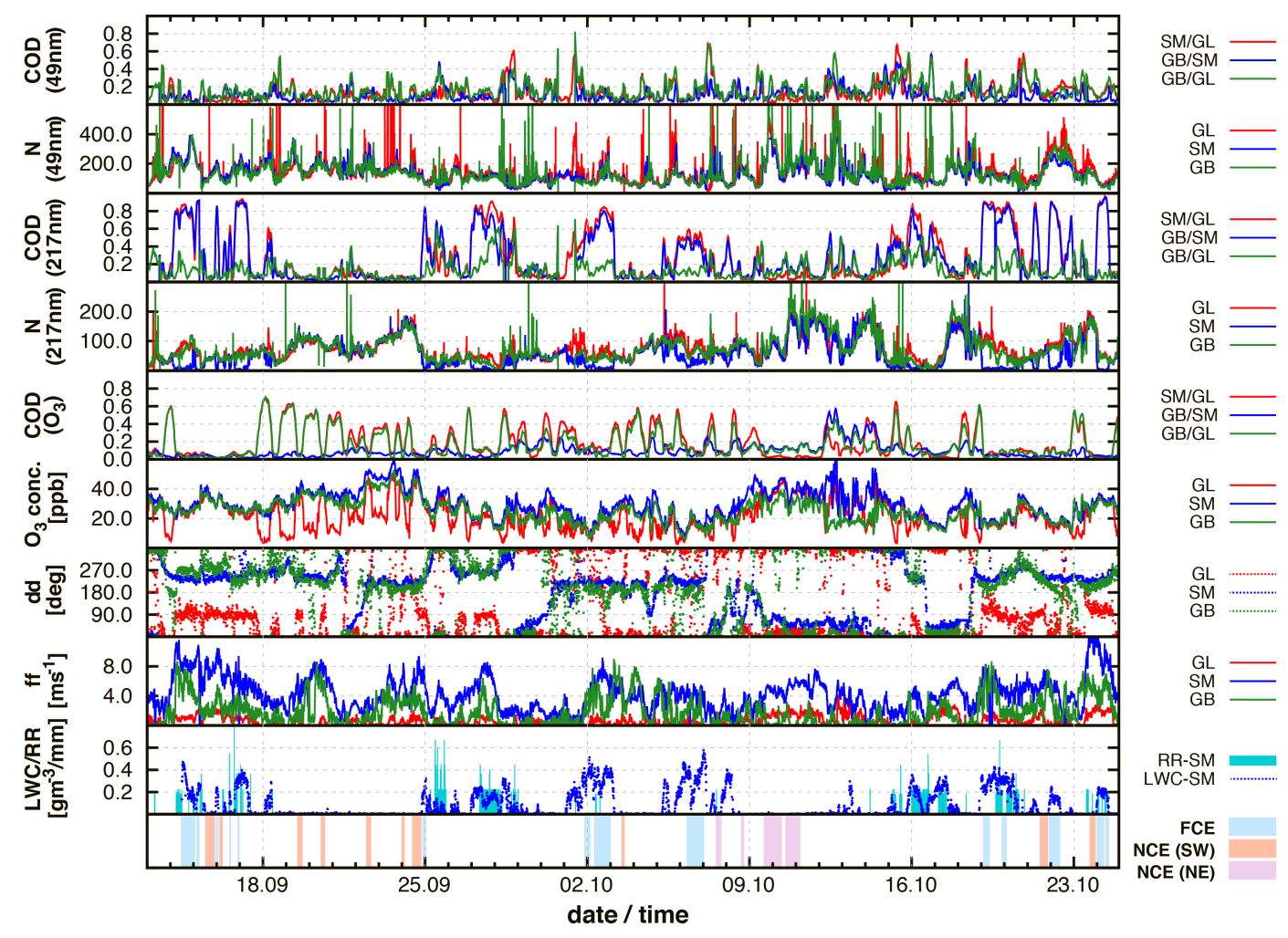

Figure 4. Depiction of the measured meteorological parameters (wind direction (dd), wind speed (ff), precipitation (RR), cloud liquid water content, LWC), ozone and particle concentrations (size bins $N_{49} \mathrm{~nm}$ and $N_{217} \mathrm{~nm}$ ) and the calculated COD values.

This result is in agreement with the time series measurements discussed above, which generally found stronger correlations between ozone concentrations at the summit and downwind measurement sites.

High COD values arise not only during periods of low wind speed but also during periods of high vertical thermal stratification. During one such period, which was observed from 18 to 25 September, night-time ozone concentrations at the upwind valley site Goldlauter were often 15-30 ppb lower than those measured at the other two stations (see Fig. 4). A difference of this magnitude cannot be explained by short-term interactions with local emissions, lowered production, and deposition only. Analysis of rawinsonde data during this time period shows distinct low-level night-time inversions, which suggests that air exchange did not occur during this time. Under such conditions, local emission (e.g. of NO into the near-ground inversion layer) and deposition processes could result in strongly lowered ozone concentrations. Support for this interpretation is provided by the fact that ozone concentrations at the upwind site largely paralleled those at the other two measurement sites during daytime, when inversions were not present. Disconnected flow was not always observed under night-time conditions, however: on the night of 23-24 September for example, the ozone concentration measured at the upwind site was substantially different from those measured at the other two stations in the evening of 23 September and the early morning hours of 24 September; at midnight, however, the three concentrations were similar. It is likely that the inversion was not present at this time. In summary, night-time inversion conditions led to the disconnection of the upwind valley site from the two downwind sites, and this disconnection is reflected in differences in the ozone concentration time series measured at this site. These differences are also reflected in the high COD values observed for this site under these conditions, which in turn indicate that connected airflow did not occur during inversion periods. Taken together, therefore, the COD values and the ozone concentration time series provide an excellent indication of the extent of local flow connectivity.

A histogram of the ozone CODs for the different measurement site combinations is provided in Fig. 5. As shown in this figure, a higher number of smaller CODs are calculated for the summit/downwind site combination $\left(\mathrm{COD}_{\mathrm{GB}-\mathrm{SM}}\right)$ : more than $60 \%$ of the ozone CODs (GE/GL) at this site are smaller than 0.15 . This observation reflects the largely more correlated ozone time series at these two locations as compared to the two location pairs that include the upwind site.

Further investigation of the three ozone concentration time series revealed good congruencies between the three measurement sites for CODs $\leq 0.1$ and acceptable congruencies for CODs $\leq 0.15$. For larger CODs, by contrast, large deviations between the three time series were observed, which 

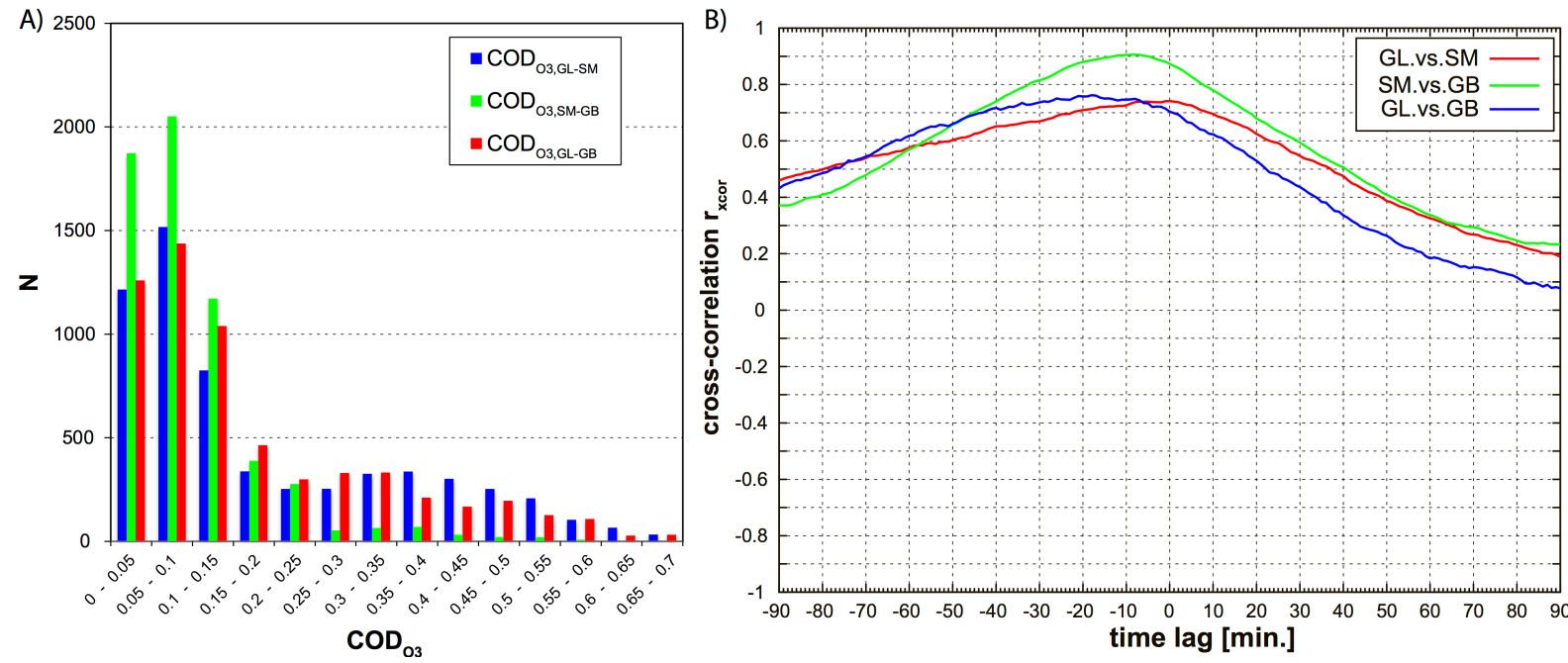

Figure 5. (a) Histogram of the calculated $\mathrm{COD}_{\mathrm{O}_{3}}$ values throughout the whole investigation period of HCCT-2010 and b calculated crosscorrelation $\left(r_{\mathrm{xcor}}\right)$ between the different sites (GL: upwind site; SM: summit site; GB: downwind site) based on measured ozone concentrations for a selected time period (14 September 2010, 11:00 CEST to 15 September 2010, 01:00 CEST).

suggests that the flow between the field sites was disconnected. Based on these findings, the ozone COD data set was used to conduct a qualitative assessment of the conditions during the campaign and to identify suitable and unsuitable time periods for further analysis. Calculated COD values were subject to the following classification scheme: (1) $\mathrm{COD} \leq 0.05$ (very good correlation), (2) $0.05 \leq \mathrm{COD} \leq 0.1$ (good correlation), (3) $0.1 \leq \mathrm{COD} \leq 0.15$ (slight correlation), (4) $0.15 \leq \mathrm{COD} \leq 0.2$ (poor correlation) and (5) $0.2 \leq \mathrm{COD}$ (very poor or no correlation). The results of the overall assessment of the flow connectivity, which included consideration of other parameters, are summarised in Table 5.

The results of cross-correlation analyses performed using the ozone concentration profiles at the three measurement sites were similar to those obtained from the COD analyses. The cross-correlation plots for each identified FCE are presented in the Supplement. A representative cross-correlation plot (from FCE1.1) is presented in Fig. 5. As shown in this figure, high cross-correlations $\left(r_{\mathrm{xcor}} \sim 0.7-0.9\right)$ were present during this time period, which suggests the existence of high flow connectivity between the three sites. The highest crosscorrelations were present between 0 and -20 min time lags. This finding implies that, during this time period, the mean air transit time between sites (e.g. from the summit to the downwind site; green line in Fig. 5) was $\sim 10 \mathrm{~min}$ and the overall mean transit time between upwind and downwind sites was $\sim 20 \mathrm{~min}$. As was observed in the COD analysis, the correlations between the summit and the downwind sites were usually somewhat higher than correlations observed for site combinations including the upwind site. It should be noted that transit times can vary considerably on the timescale of a FCE period. Therefore, the Supplement includes cross-correlation plots not only for the entire duration of each period but also for shorter time intervals (typically $3 \mathrm{~h}$ ) during each period. The results of the cross-correlation analyses for each of the FCEs selected for overall assessment are summarised in Table 5.

\subsubsection{Overflow characterisation with aerosol particle distribution data}

In addition to the ozone concentration measurements described in the previous section, particle number concentrations from the $49 \mathrm{~nm}\left(N_{49 \mathrm{~nm}}\right)$ and $217 \mathrm{~nm}\left(N_{217} \mathrm{~nm}\right)$ size bins of the SMPSs were used for the assessment of flow connectivity between the three measurement sites and the assessment of prevailing cloud conditions. The measured particle number concentrations at the three sites and the corresponding three COD values are presented in Fig. 4. These data clearly show that the $N_{49 \mathrm{~nm}}$ and $N_{217 \mathrm{~nm}}$ values at the different sites are variable, and therefore that they are suitable for use in COD analysis.

For the most part, the $N_{217} \mathrm{~nm}$ plot shows quite good agreement between the measured data obtained at the upwind and downwind sites. Number concentrations $\left(N_{217} \mathrm{~nm}\right)$ obtained at the summit site, by contrast, show larger differences under some conditions. As can be seen from the plot, the $N_{217 n m}$ bin always shows very low concentrations in the presence of clouds or fogs, which is attributable to cloud condensation nuclei (CCN) activation in this size range. This behaviour leads to large COD values $\left(\mathrm{COD}_{N 217 \mathrm{~nm}}>0.8\right)$ during cloud conditions at the summit site and non-cloud conditions in the upwind and downwind valleys.

For this reason, the $N_{217 \mathrm{~nm}}$ parameter can be used in addition to measurements of liquid water content at Mt. Schmücke - to characterise cloud/fog conditions at 
the measurement sites and to distinguish between flow conditions with and without cloud interaction. In order to separate time intervals with clouds from those without clouds (i.e. with/without activation of accumulation mode particles), a critical $\operatorname{COD}_{N 217 \mathrm{~nm}}$ value was defined: for $\mathrm{COD}_{N 217 \mathrm{~nm}}>0.4$, activation of accumulation mode particles is expected and thus cloud conditions are assumed to have been present at the summit site.

Unlike the $N_{217} \mathrm{~nm}$ plot, the $N_{49} \mathrm{~nm}$ plot shows quite good agreement between the measured data obtained at all three measurement sites. The calculated $\mathrm{COD}_{N 49 \mathrm{~nm}}$ shows the lowest values during weather situations with both SW and NE winds, which indicates that good flow connectivity exists under these conditions. Comparison of the $N_{49} \mathrm{~nm}$ time series with the corresponding calculated $\mathrm{COD}_{N 49 \mathrm{~nm}}$ values shows that larger deviations between measured concentration profiles coincide directly with higher $\operatorname{COD}_{N 49}$ nm values. While $\mathrm{COD}_{N 49 \mathrm{~nm}}$ values generally paralleled $\mathrm{COD}_{\mathrm{O}_{3}}$ values, the $\mathrm{COD}_{N 49 \mathrm{~nm}}$ time series typically exhibited more noise. This enhanced noise most likely arose as a result of the coarser time resolution of the particle concentration input data and the overall lower variability in $\mathrm{COD}_{N 49 \mathrm{~nm}}$ values as compared to $\mathrm{COD}_{\mathrm{O}_{3}}$ values.

Overall, examination of the $N_{49 \mathrm{~nm}}$ temporal profiles revealed that reasonable congruencies between the three profiles existed for $\operatorname{COD}_{N 49 \mathrm{~nm}} \leq 0.2$. For larger $\operatorname{COD}_{N 49 \mathrm{~nm}}$ values, larger deviations were present, which suggests that a disconnection of the flow between the three field sites most likely existed. Based on this finding, and those obtained in previous studies (see Sect. 2), the $\operatorname{COD}_{N 49 \mathrm{~nm}}$ data set was used to conduct a qualitative assessment of the conditions during the campaign and to identify time periods with and without connected flow conditions. Calculated COD values were subject to the following classification scheme: (1) $\operatorname{COD}_{N 49 \mathrm{~nm}} \leq 0.05$ (very good correlation), (2) $0.05 \leq \mathrm{COD}_{N 49 \mathrm{~nm}} \leq 0.1$ (good correlation), (3) $0.1 \leq \mathrm{COD}_{N 49 \mathrm{~nm}} \leq 0.15$ (satisfactory correlation), (4) $0.15 \leq \operatorname{COD}_{N 49 \mathrm{~nm}} \leq 0.2$ (slight correlation) and (5) for $0.2 \leq \mathrm{COD}_{N 49 \mathrm{~nm}}$ (very poor or no correlation). The $\mathrm{COD}_{N 49 \mathrm{~nm}}$ data set was then colour-coded according to cloud conditions and to the above classifications of connected flow conditions (see the Supplement). These results were used in the selection of the most suitable periods for further investigation (see Sect. 3.2.3). The results of the overall assessment of the flow connectivity, which included consideration of other parameters, are summarised in Table 5.

\subsubsection{Selection of potentially suitable investigation periods}

The main goal of the present study was to quantitatively and objectively identify periods of time during the HCCT-2010 campaign when the three measurement sites experienced connected flow conditions. Full-cloud events (FCEs), which we define as time periods with connected SW flow condi-

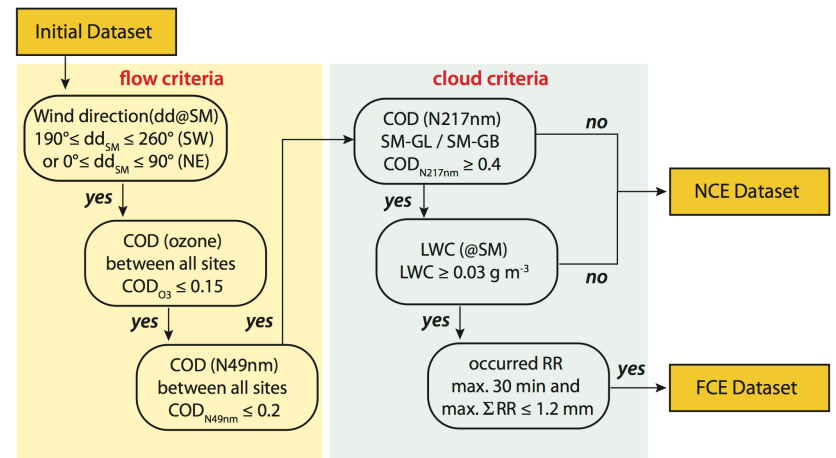

Figure 6. Schematic depiction of the FCE and NCE selection procedure.

tions and cloud conditions present only at the Mt. Schmücke summit site, and non-cloud events (NCEs), which we define as periods with connected SW or NE flow conditions and no clouds/fog at any site, were identified according to the twostep procedure shown in Fig. 6.

According to this procedure, periods with connected flow condition (SW/NE wind sector) were first identified according to the flow criteria described previously. Then, the measured LWC at the Mt. Schmücke site was used to evaluate the cloud conditions, and the CODs of the aerosol number concentration $\left(N_{217 \mathrm{~nm}}\right.$, activated $\mathrm{CCN}$ bin under typical cloud/fog conditions) were used both to identify cloud/noncloud conditions at the summit and to exclude conditions with fog at the valley sites. Finally, only periods with insignificant amounts of precipitation (RR: precipitation rate during the last $30 \mathrm{~min}$ ) at each of the three sites were selected. The entire data set, including meteorological data, calculated CODs, and a table describing the identified FCEs and NCEs, is given in the Supplement. A brief summary of the most important parameters associated with each of the selected FCEs is given in Table 3. The final evaluation of all of the FCEs is summarised in Table 5.

The name associated with each of the identified FCEs reflects their chronological occurrence during HCCT-2010. Periods of prolonged cloud presence, which could also include small cloud-free breaks (i.e. conditions with LWC values close to zero), were determined based on the LWC time series measured at Mt. Schmücke and numbered chronologically. Each defined cloud period was further subdivided into individual uninterrupted cloud event periods (i.e. continuous cloud conditions, without very low LWC values). For example, the event FCE1.1 refers to the first (uninterrupted) part of the first prolonged cloud period that occurred at Mt. Schmücke during the experiment. 
Table 3. Description of cloud conditions and overview of the statistical analysis of connected flow: mean coefficient of divergence (COD) values; cloud liquid water content (LWC); and wind direction (dd), speed (ff), and precipitation (RR, total precipitation amount during the FCE) at the Mt. Schmücke summit site are presented for each FCE.

\begin{tabular}{|c|c|c|c|c|c|c|c|c|c|c|c|c|c|}
\hline FCE (time (CEST)) & $\begin{array}{l}\text { LWC } \\
\mathrm{g} \mathrm{m}^{-3}\end{array}$ & $\begin{array}{l}\text { dd } \\
\text { SM } \\
\text { deg }\end{array}$ & $\begin{array}{c}\mathrm{ff} \\
\mathrm{SM} \\
\mathrm{ms}^{-1}\end{array}$ & $\begin{array}{c}\text { COD } \\
\text { SM-GL } \\
\mathrm{O}_{3}\end{array}$ & $\begin{array}{c}\text { COD } \\
\text { GB-SM } \\
\mathrm{O}_{3}\end{array}$ & $\begin{array}{c}\text { COD } \\
\text { GB-GL } \\
\mathrm{O}_{3}\end{array}$ & $\begin{array}{c}\text { COD } \\
\text { SM-GL } \\
N_{49 \mathrm{~nm}}\end{array}$ & $\begin{array}{c}\text { COD } \\
\text { GB-SM } \\
N_{49 \text { nm }}\end{array}$ & $\begin{array}{c}\text { COD } \\
\text { GB-GL } \\
N_{49 \text { nm }}\end{array}$ & $\begin{array}{c}\text { COD } \\
\text { SM-GL } \\
N_{217 n m}\end{array}$ & $\begin{array}{c}\text { COD } \\
\text { GB-SM } \\
N_{217 n m}\end{array}$ & $\begin{array}{c}\text { COD } \\
\text { GB-GL } \\
N_{217 n m}\end{array}$ & $\begin{array}{l}\mathrm{RR} \\
\mathrm{SM} \\
\mathrm{mm}\end{array}$ \\
\hline FCE1.1 (14.09.10 11:00 - 15.09.10 01:50) & 0.25 & 236 & 8.2 & 0.06 & 0.04 & 0.03 & 0.06 & 0.08 & 0.03 & 0.74 & 0.75 & 0.14 & 1.2 \\
\hline FCE1.2 (15.09.10 03:00-15.09.10 06:20) & 0.20 & 231 & 9.6 & 0.04 & 0.05 & 0.03 & 0.04 & 0.04 & 0.02 & 0.86 & 0.88 & 0.13 & 0.4 \\
\hline FCE2.1 (15.09.10 23:00-16.09.10 02:00) & 0.17 & 240 & 8.7 & 0.02 & 0.02 & 0.02 & 0.03 & 0.08 & 0.09 & 0.71 & 0.72 & 0.09 & 0.0 \\
\hline FCE4.1 (16.09.10 13:10-16.09.10 15:00) & 0.13 & 243 & 7.4 & 0.06 & 0.03 & 0.04 & 0.09 & 0.10 & 0.17 & 0.57 & 0.51 & 0.14 & 0.8 \\
\hline FCE5.1 (16.09.10 21:40-16.09.10 23:50) & 0.30 & 239 & 6.3 & 0.05 & 0.03 & 0.03 & 0.04 & 0.10 & 0.12 & 0.89 & 0.87 & 0.13 & 0.0 \\
\hline FCE7.1 (24.09.10 21:10-25.09.10 00:50) & 0.20 & 228 & 6.7 & 0.04 & 0.04 & 0.03 & 0.05 & 0.09 & 0.12 & 0.69 & 0.67 & 0.07 & 0.0 \\
\hline FCE11.2 (01.10.10 20:50-02.10.10 03:10) & 0.37 & 222 & 3.7 & 0.08 & 0.10 & 0.14 & 0.09 & 0.06 & 0.12 & 0.59 & 0.51 & 0.15 & 0.0 \\
\hline FCE11.3 (02.10.10 07:10-03.10.10 00:30) & 0.32 & 220 & 6.3 & 0.12 & 0.09 & 0.06 & 0.13 & 0.08 & 0.14 & 0.76 & 0.69 & 0.17 & 0.5 \\
\hline FCE13.3 (06.10.10 06:50-07.10.10 01:00) & 0.32 & 223 & 4.2 & 0.10 & 0.06 & 0.07 & 0.11 & 0.09 & 0.15 & 0.50 & 0.41 & 0.12 & 0.0 \\
\hline FCE22.0 (19.10.10 01:50-19.10.10 09:00) & 0.29 & 233 & 5.1 & 0.07 & 0.05 & 0.03 & 0.18 & 0.09 & 0.12 & 0.88 & 0.85 & 0.12 & 0.0 \\
\hline FCE22.1 (19.10.10 21:10-20.10.10 02:30) & 0.31 & 248 & 4.7 & 0.07 & 0.05 & 0.09 & 0.09 & 0.04 & 0.09 & 0.83 & 0.78 & 0.13 & 0.2 \\
\hline FCE24.0 (21.10.10 22:10-22.10.10 10:00) & 0.14 & 241 & 4.9 & 0.09 & 0.03 & 0.08 & 0.15 & 0.09 & 0.07 & 0.78 & 0.76 & 0.06 & 0.0 \\
\hline FCE26.1 (23.10.10 23:40-24.10.10 07:20) & 0.19 & 233 & 9.7 & 0.03 & 0.04 & 0.01 & 0.10 & 0.04 & 0.09 & 0.86 & 0.84 & 0.08 & 0.8 \\
\hline FCE26.2 (24.10.10 08:40-24.10.10 12:20) & 0.15 & 239 & 9.0 & 0.03 & 0.03 & 0.01 & 0.19 & 0.08 & 0.23 & 0.84 & 0.83 & 0.07 & 0.4 \\
\hline
\end{tabular}

\subsection{Overflow characterisation with non-dimensional parameters}

The calculated Froude $(F r)$ and Richardson $(R i)$ numbers for the different rawinsonde observations (from Meiningen, which is located $\sim 30 \mathrm{~km}$ upwind of Mt. Schmücke) during or near the selected FCEs/NCEs (with SW flow conditions only), as well as associated remarks are listed in Table 4. Since the focus of the present study is the FCEs, only the $\mathrm{Fr}$ and $R i$ numbers related to the FCEs are discussed here in detail.

As can be seen from Table 4, the $F r$ number predicts a stagnant flow/area during only a few FCEs; during the majority of the identified FCEs, no blocking or only a slightly decelerated flow was present. The calculated values show that the flow conditions were largely determined by the extent of atmospheric stratification and, in some cases, by the wind speed conditions. Large $F r$ numbers coincided always with large $R i$ numbers, which indicated very statically stable conditions. Under these stable conditions, however, acceptable flow conditions could still be achieved: on 14 September (14:00 CEST), for example, high mean wind speeds $\left(8 \mathrm{~m} \mathrm{~s}^{-1}\right)$ allowed for air flow over the mountain ridge.

These non-dimensional parameters compare well with the calculated COD values for ozone and the $N_{49} \mathrm{~nm}$ size bin (COD between the up and downwind site): higher $F r$ and higher $R i$ numbers, which indicate a potential blocking of the airflow, generally coincide with higher COD values, which reflect deviations between the different sites.

During FCE 11.3, for example, the $F r$ number on 2 October (14:00 CEST) was 0.81, which indicates that airflow over the mountain range was possible; by the early morning hours of 3 October (02:00 CEST), however, the calculated $F r$ (1.31) and $R i$ (7.19) numbers imply a stronger deceleration of the flow under very stable conditions. This latter result is confirmed by the ozone COD analysis, which revealed CODs > 0.2 after 00:30 (CEST). Sim- ilar results were obtained during FCE 13.3, in which better flow conditions are predicted by the $\mathrm{Fr}$ number during the daytime (14:00 CEST) on 6 October $(F r=0.85$; $\left.\mathrm{COD}_{\mathrm{O}_{3}}=0.09 ; \mathrm{COD}_{N 49 \mathrm{~nm}}=0.12\right)$ than during the subsequent night-time (02:00 CEST) observation on 7 October $\left(F r=1.16 ; \mathrm{COD}_{\mathrm{O}_{3}}=0.14 ; \mathrm{COD}_{N 49 \mathrm{~nm}}=0.27\right)$. During this latter period, a disconnection of the upwind site from the two other sites appeared to be present after 01:00 CEST (see Table 4 and the time-resolved COD analysis data in the Supplement).

\subsection{Detailed meteorological characterisation of the identified FCEs}

Meteorological conditions, including the separation of orographic and non-orographic clouds, the detection of frontal processes, the stability of air mass advection (local/synoptic scale) and the cloud conditions (LWC, precipitation, cloud base height), were examined in detail for each of the identified FCEs. These data were obtained from locally measured meteorological and microphysical data, rawinsonde observations, satellite pictures, ceilometer data, and calculated backward trajectories. For reasons of clarity, all detailed information for each FCE is given in the Supplement.

\subsection{Model-based characterisation of the flow conditions during FCEs}

The extent to which the identified FCEs met the required overflow conditions was also characterised using the wind field predictions of the COSMO model. Figures showing the horizontal wind conditions predicted by the COSMO model in the Mt. Schmücke area for each of the selected FCEs are presented in the Supplement.

A nearly constant wind field, with wind arrows of approximately the same orientation (SW) and length (i.e. the same wind speed and direction) is a good indication for mountain 
Table 4. Froude numbers $(F r)$, Richardson numbers $(R i)$, and rawinsonde observational data (from the Meiningen German Weather Service station) used to calculate these parameters, during or near all identified full-cloud events (FCEs) and non-cloud events (NCEs).

\begin{tabular}{|c|c|c|c|c|c|c|c|c|c|c|}
\hline $\begin{array}{l}\text { Date/time } \\
(\mathrm{CEST})\end{array}$ & $\begin{array}{l}U / \mathrm{dd} \\
\left(\mathrm{ms}^{-1}\right) /(\mathrm{deg})\end{array}$ & $\begin{array}{r}\mathrm{d} \Theta / \mathrm{d} z \\
\left(\mathrm{~K} \mathrm{~m}^{-1}\right)\end{array}$ & $\begin{array}{r}\mathrm{d} U / \mathrm{d} z \\
\left(\mathrm{~s}^{-1}\right)\end{array}$ & $\begin{array}{c}N^{2} \\
\left(\mathrm{~s}^{-1}\right)\end{array}$ & $F r$ & $R i$ & $\begin{array}{l}\text { Overflow } \\
\text { y: yes; n: no }\end{array}$ & Stability & $\begin{array}{l}\text { Ozone } \\
\text { COD }\end{array}$ & $\begin{array}{c}N 49 \mathrm{~nm} \\
\mathrm{COD}\end{array}$ \\
\hline $14-09,14: 00$ & $8 / 240$ & 0.0054 & 0.0107 & 0.0002 & 0.85 & 1.62 & $\mathrm{y}$ (decelerated) & stable & 0.02 & 0.05 \\
\hline $15-09,02: 00$ & $6 / 225$ & 0.0024 & 0.014 & 0.0001 & 0.68 & 0.42 & $\mathrm{y}$ & stable & 0.03 & 0.02 \\
\hline $15-09,14: 00$ & $6 / 235$ & -0.0033 & 0.0186 & -0.0001 & 0 & -0.32 & $\mathrm{y}^{*}$ & unstable & 0.02 & 0.07 \\
\hline $16-09,02: 00$ & $5 / 240$ & 0.0034 & 0.0159 & 0.0001 & 1.13 & 0.46 & $\mathrm{y}$ (decelerated) & stable & 0.02 & 0.09 \\
\hline $16-09,14: 00$ & $6 / 250$ & -0.0011 & 0.0112 & 0 & $\rightarrow 0.00$ & -0.30 & $\mathrm{y}^{*}$ & unstable & 0.04 & 0.17 \\
\hline $17-09,02: 00$ & $6 / 270$ & 0.0049 & 0.0147 & 0.0002 & 1.1 & 0.77 & y (decelerated) & stable & 0.03 & 0.08 \\
\hline $19-09,14: 00$ & $6 / 250$ & -0.0031 & 0.0086 & -0.0001 & $\rightarrow 0.00$ & -1.40 & $y^{*}$ & unstable & 0.04 & 0.07 \\
\hline $20-09,14: 00$ & $6 / 235$ & 0.0028 & 0.0106 & 0.0001 & 0.73 & 0.83 & $\mathrm{y}$ & stable & 0.01 & 0.03 \\
\hline $22-09,14: 00$ & $3 / 220$ & -0.0017 & 0.0024 & -0.0001 & $\rightarrow 0.00$ & -9.31 & $y^{*}$ & unstable & 0.03 & 0.16 \\
\hline $24-09,02: 00$ & $8 / 220$ & 0.0147 & 0.0209 & 0.0005 & 1.27 & 1.14 & $\mathrm{y}$ (decelerated) & stable & 0.06 & 0.05 \\
\hline $24-09,14: 00$ & $-/ 210$ & - & - & - & - & - & - & - & 0.03 & 0.13 \\
\hline $25-09,02: 00$ & $4 / 270$ & 0.0032 & 0.0049 & 0.0001 & 1.39 & 4.49 & y (decelerated) & stable & 0.10 & 0.15 \\
\hline $27-09,02: 00$ & $5 / 270$ & 0.0041 & 0.0121 & 0.0001 & 1.12 & 0.97 & $\mathrm{y}$ (decelerated) & stable & 0.12 & 0.11 \\
\hline $27-09,14: 00$ & $3 / 260$ & 0.0004 & 0.0075 & 0 & 0.55 & 0.22 & $\mathrm{y}$ & stable & 0.12 & 0.16 \\
\hline $28-09,14: 00$ & $6 / 230$ & 0.0021 & 0.0022 & 0.0001 & 0.73 & 15.22 & y & stable & 0.28 & 0.18 \\
\hline $01-10,14: 00$ & $3 / 340$ & 0.0067 & 0.0008 & 0.0002 & 2.2 & 326.54 & n (stagnant area) & stable & 0.07 & 0.29 \\
\hline $02-10,02: 00$ & $3 / 225$ & 0.0064 & 0.0063 & 0.0002 & 2.33 & 5.6 & n (stagnant area) & stable & 0.13 & 0.08 \\
\hline $02-10,14: 00$ & $6 / 220$ & 0.0034 & 0.0118 & 0.0001 & 0.81 & 0.82 & y (decelerated) & stable & 0.06 & 0.18 \\
\hline $03-10,02: 00$ & $6 / 220$ & 0.0068 & 0.0057 & 0.0002 & 1.31 & 7.19 & y (decelerated) & stable & 0.29 & 0.10 \\
\hline $03-10,14: 00$ & $7 / 195$ & 0.0023 & 0.009 & 0.0001 & 0.58 & 0.97 & $\mathrm{y}$ & stable & 0.03 & 0.20 \\
\hline $05-10,14: 00$ & $6 / 240$ & 0.0063 & 0.0112 & 0.0002 & 1.2 & 1.72 & $\mathrm{y}$ (decelerated) & stable & 0.18 & 0.25 \\
\hline $06-10,02: 00$ & $5 / 220$ & 0.0112 & 0.0174 & 0.0004 & 1.75 & 1.26 & y (stagnant flow) & stable & 0.17 & 0.06 \\
\hline $06-10,14: 00$ & $5 / 225$ & 0.0027 & 0.0053 & 0.0001 & 0.85 & 3.23 & y (decelerated) & stable & 0.09 & 0.13 \\
\hline $07-10,02: 00$ & $5 / 240$ & 0.0036 & 0.0085 & 0.0001 & 1.16 & 1.68 & $\mathrm{y}$ (decelerated) & stable & 0.14 & 0.27 \\
\hline $07-10,14: 00$ & $2 / 55$ & 0.0024 & 0.0029 & 0.0001 & 2.43 & 10.03 & n (stagnant area) & stable & 0.05 & 0.21 \\
\hline $08-10,14: 00$ & $4 / 60$ & -0.0015 & 0.0019 & -0.0001 & $\rightarrow 0.00$ & -13.79 & $\mathrm{y}^{*}$ & unstable & 0.11 & 0.08 \\
\hline $09-10,14: 00$ & $6 / 80$ & 0.0032 & 0.0151 & 0.0001 & 0.85 & 0.48 & $\mathrm{y}$ (decelerated) & stable & 0.13 & 0.14 \\
\hline $10-10,02: 00$ & $7 / 85$ & 0.0151 & 0.0219 & 0.0005 & 1.66 & 1.09 & y (stagnant flow) & stable & 0.09 & 0.09 \\
\hline $11-10,02: 00$ & $7 / 85$ & 0.0187 & 0.0182 & 0.0006 & 1.78 & 1.95 & y (stagnant flow) & stable & 0.09 & 0.11 \\
\hline $11-10,14: 00$ & $6 / 70$ & 0.0021 & 0.0155 & 0.0001 & 0.73 & 0.3 & $\mathrm{y}$ & stable & 0.09 & 0.04 \\
\hline $12-10,02: 00$ & $4 / 45$ & 0.0175 & 0.0064 & 0.0006 & 3.32 & 14.76 & n (stagnant area) & stable & 0.11 & 0.06 \\
\hline $13-10,14: 00$ & $4 / 65$ & 0.007 & 0.009 & 0.0002 & 1.83 & 2.97 & y (stagnant flow) & stable & 0.31 & 0.15 \\
\hline $16-10,02: 00$ & $4 / 245$ & 0.0037 & 0.0087 & 0.0001 & 1.51 & 1.67 & y (stagnant flow) & stable & 0.12 & 0.20 \\
\hline $19-10,02: 00$ & $6 / 230$ & 0.0062 & 0.0118 & 0.0002 & 1.12 & 1.57 & $\mathrm{y}$ (decelerated) & stable & 0.05 & 0.10 \\
\hline $19-10,14: 00$ & $7 / 230$ & 0.002 & 0.0121 & 0.0001 & 0.6 & 0.47 & $\mathrm{y}$ & stable & 0.02 & 0.06 \\
\hline $20-10,02: 00$ & $6 / 245$ & 0.0063 & 0.0185 & 0.0002 & 1.16 & 0.64 & $\mathrm{y}$ (decelerated) & stable & 0.06 & 0.07 \\
\hline $21-10,14: 00$ & $7 / 250$ & -0.0011 & 0.0069 & 0 & $\rightarrow 0.00$ & -0.79 & $\mathrm{y}^{*}$ & unstable & 0.03 & 0.11 \\
\hline $22-10,02: 00$ & $7 / 240$ & 0.0101 & 0.0138 & 0.0004 & 1.23 & 1.88 & $\mathrm{y}$ (decelerated) & stable & 0.12 & 0.04 \\
\hline $23-10,14: 00$ & $8 / 225$ & 0.0128 & 0.02 & 0.0005 & 1.25 & 1.14 & $\mathrm{y}$ (decelerated) & stable & 0.09 & 0.24 \\
\hline $24-10,02: 00$ & $13 / 225$ & 0.0038 & 0.0286 & 0.0001 & 0.42 & 0.16 & $\mathrm{y}$ & stable & 0.01 & 0.08 \\
\hline $24-10,14: 00$ & $7 / 245$ & 0 & 0.0073 & 0 & 0 & 0 & $\mathrm{y}$ & neutral & 0.02 & 0.19 \\
\hline
\end{tabular}

overflow conditions without a deceleration/blocking of the flow, without significant downward mixing of air from higher levels, and without a circulation around the Thuringian Forest. This condition was fulfilled for all FCEs during September and for FCE26.1/FCE26.2 in October, in which very constant SW flow conditions were predicted by COSMO. For example, as illustrated in Fig. 7, FCE7.1 showed a very homogeneous regional wind field with similar wind directions and wind speeds before, on top and behind the mountain ridge, which indicates an adequate flow over the mountain (i.e. without an upwind deceleration of the incoming flow and almost no entrainment of higher-level air).
The other FCEs (11.2, 11.3, 13.3 (in part), 22.0 (in part), 22.1, and 24.0), by contrast, showed less congruent wind directions and wind speeds before, on top and behind the mountain ridge - for these FCEs, the COSMO model predicted an upwind blocking, at least in part. For example, as shown in Fig. 7, the model predicted decelerated flow conditions in the upwind area and stronger winds in the downwind area during FCE 24.0. The latter prediction indicates the presence of downdrafts in the lee of the mountain ridge and, thus, entrainment of air from higher altitudes.

The COSMO-predicted wind conditions during each of the identified FCEs are presented in Table 5. In general, these 
Table 5. Summary of the meteorological and overflow conditions during the identified FCEs, including a conclusive assessment of their suitability for future analyses. In brackets, the Supplement section is given where the utilised material for each FCE is obtainable.

\begin{tabular}{|c|c|}
\hline $\begin{array}{l}\text { FCE } \\
\text { Date/Time (CEST) } \\
\text { (Offline sampling) }\end{array}$ & Remarks on meteorological conditions and flow connectivity \\
\hline $\begin{array}{l}\text { FCE1.1 } \\
\text { 14-09-2010 11:00 } \\
\text { to } 15-09-201001: 50 \\
(14-09-201011: 00 \\
\text { to 15-09-2010 02:00) } \\
\text { [Supplement section A] }\end{array}$ & $\begin{array}{l}\text { Mostly good overflow conditions, with low } \mathrm{COD}_{\mathrm{O}_{3}} \text { (mean } \mathrm{COD}_{\mathrm{O}_{3}}<0.06 \text { at all sites) and } \mathrm{COD}_{N 49 \mathrm{~nm}} \\
(\text { mean } \mathrm{COD} N 49 \mathrm{~nm}, \mathrm{GL}-\mathrm{GB}<0.08) \text { values, congruent } \mathrm{O}_{3} \text { concentration profiles, CODs and cross- } \\
\text { correlation analysis showed less sufficient flow conditions around 17:30-19:00 and particularly af- } \\
\text { ter midnight (correlations with the upwind site were significantly lower, which indicates that slight } \\
\text { LUV blocking effects were possible), stable } \mathrm{SW} \text { flow conditions }\left(\mathrm{dd}_{\mathrm{SM}}=236^{\circ}\right) \text {, moderate wind speed } \\
\left(\mathrm{ff}_{\mathrm{SM}}=8.2 \mathrm{~m} \mathrm{~s}^{-1}\right) \text {, precipitation at the beginning and end (total } \mathrm{RR}_{\mathrm{SM}} \approx 1.2 \mathrm{~mm} \text { ) of the FCE, longest } \\
\text { offline sampling period }(15 \mathrm{~h}) \text {, cold front at the end of the FCE, frontal cloudiness, stable thermal strat- } \\
\text { ification, quite stable trajectories and air mass advection, almost suitable overflow conditions predicted } \\
\text { by the COSMO model (slightly decelerated flow particularly between 04:00 p.m. and 06:00 p.m.) } \\
\rightarrow \text { Suitable FCE: adequate meteorological/connected flow conditions }\end{array}$ \\
\hline
\end{tabular}

FCE1.2

$15-09-2010$

03:00-06:20

(no offline sampling) [Supplement section B]
Good overflow conditions, with low $\mathrm{COD}_{\mathrm{O}_{3}}$ (mean $\mathrm{COD}_{\mathrm{O}_{3}}<0.05$ at all sites) and $\mathrm{COD}_{N 49 \mathrm{~nm}}$ (mean $\mathrm{COD}_{N 49 \mathrm{~nm}, \mathrm{GL}-\mathrm{GB}} \approx 0.02$ ) values, very congruent $\mathrm{O}_{3}$ concentration profiles, reasonable cross-correlations $\left(r_{\mathrm{xcor}, \mathrm{GB}-\mathrm{GL}} \approx 0.7\right)$, stable $\mathrm{SW}$ flow conditions $\left(\mathrm{dd}_{\mathrm{SM}}=231^{\circ}\right)$, high wind speed $\left(\mathrm{ff}_{\mathrm{SM}}=9.6 \mathrm{~m} \mathrm{~s}^{-1}\right)$, probably stable thermal stratification, slight precipitation at all sites $\left(\mathrm{RR}_{\mathrm{SM}} \approx 0.4 \mathrm{~mm}\right)$, increasing LWC from 0.05 to $0.28 \mathrm{~g} \mathrm{~m}^{-3}$, unsteady cloud base height, short duration $(3.33 \mathrm{~h}$ ), suitable overflow conditions predicted by the COSMO model

$\rightarrow$ Suitable, although short-duration, FCE: adequate meteorological/connected flow conditions

\section{FCE2.1}

15-09-2010 23:00

to $16-09-2010$ 02:00

(no offline sampling)

[Supplement section C]
Good overflow conditions, with low $\mathrm{COD}_{\mathrm{O}_{3}}$ (permanently below 0.02 ) and $\mathrm{COD}_{N 49 \mathrm{~nm}}$ (mean $\mathrm{COD}_{N 49 \mathrm{~nm}, \mathrm{GL}-\mathrm{GB}} \approx 0.09$ ) values, very congruent $\mathrm{O}_{3}$ concentration profiles, high cross-correlations $\left(0.6<r_{\text {xcor }}<0.8\right)$, stable thermal stratification, slightly decelerated flow possible $(F r=1.13)$, moderate to high wind speed ( $\mathrm{ff}_{\mathrm{SM}}$ increasing from $\sim 7 \mathrm{~m} \mathrm{~s}^{-1}$ to $10.5 \mathrm{~m} \mathrm{~s}^{-1}$ ), increasing cloud base height at the end of the FCE $(>300 \mathrm{~m})$, stable SW wind conditions $\left(\mathrm{dd}_{\mathrm{SM}} \approx 240^{\circ}\right)$, relatively low LWC (mean $0.17 \mathrm{~g} \mathrm{~m}^{-3}$ ), short duration $(3 \mathrm{~h})$, no precipitation, clouds probably not purely orographically induced, suitable overflow conditions predicted by the COSMO model

$\rightarrow$ Suitable FCE: adequate meteorological/connected flow conditions

\section{FCE4.1}

16-09-2010

13:10-15:00

(no offline sampling) [Supplement section D]
Less sufficient overflow conditions, with low $\mathrm{COD}_{\mathrm{O}_{3}}$ values (mean $\mathrm{COD}_{\mathrm{O}_{3}}<0.07$ at all sites) but high $\mathrm{COD}_{N 49 \mathrm{~nm}}$ values (mean $\mathrm{COD}_{N 49 \mathrm{~nm}, \mathrm{GL}-\mathrm{GB}} \approx 0.17$ ), congruent $\mathrm{O}_{3}$ concentration profiles but low cross-correlations, especially for the downwind site (slight disconnection possible), unstable wind direction changing from SW $\left(224^{\circ}\right)$ to WSW $\left(254^{\circ}\right)$ within $2 \mathrm{~h}$, moderate wind speeds $\left(\mathrm{ff}_{\mathrm{SM}}=7.4 \mathrm{~m} \mathrm{~s}^{-1}\right)$, changing cloud base height (partially above $350 \mathrm{~m}$ at the end of the FCE), labile thermal stratification (possible entrainment), low mean LWC $\left(0.13 \mathrm{~g} \mathrm{~m}^{-3}\right)$, slight precipitation at all sites during the event $\left(\mathrm{RR}_{\mathrm{SM}}<0.8 \mathrm{~mm}\right)$ due to an occlusion (frontal cloudiness), short duration $(2 \mathrm{~h})$, suitable overflow conditions predicted by the COSMO model (but westerly winds predicted) $\rightarrow$ Probably useful FCE: slightly limited meteorological and connected flow conditions
FCE5.1

$16-09-2010$

$21: 40-23: 50$

(no offline sampling) [Supplement section E]

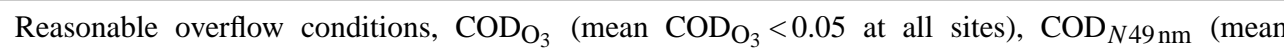
$\left.\mathrm{COD}_{N 49 \mathrm{~nm}, \mathrm{GL}-\mathrm{GB}} \approx 0.12\right)$, lower $\mathrm{COD}_{N 49 \mathrm{~nm}, \mathrm{GL}-\mathrm{SM}}(\approx 0.04)$, congruent $\mathrm{O}_{3}$ concentration profiles, moderate wind speeds $\left(\mathrm{ff}_{\mathrm{SM}}=6.3 \mathrm{~m} \mathrm{~s}^{-1}\right)$, stable thermal stratification, stable WSW flow conditions $\left(\mathrm{dd}_{\mathrm{SM}}=239^{\circ}\right)$, slightly decelerated flow possible $(F r=1.1)$, quite stable cloud base height (200-250 m), stable and high LWC (mean $0.3 \mathrm{~g} \mathrm{~m}^{-3}$ ), no precipitation, short duration ( $\left.2 \mathrm{~h} 10 \mathrm{~min}\right)$, mostly good overflow conditions predicted by the COSMO model (small upwind deceleration of the flow towards the end of the FCE)

$\rightarrow$ Suitable, although short-duration, FCE: adequate meteorological/connected flow conditions 
Table 5. Continued.

\begin{abstract}
FCE7.1
24-09-2010 21:10

to $25-09-201000: 50$

(24-09-2010 23:45

to $25-09-2010$ 01:45)

[Supplement section F]

Good overflow conditions, with low $\mathrm{COD}_{\mathrm{O}_{3}}$ values (mean $\mathrm{COD}_{\mathrm{O}_{3}}<0.04$ at all sites) and moderate $\mathrm{COD}_{N 49 \mathrm{~nm}}$ values (mean $\mathrm{COD}_{N 49 \mathrm{~nm}, \mathrm{GL}-\mathrm{GB}}<0.12$ ), congruent $\mathrm{O}_{3}$ concentration profiles, very high cross-correlations $\left(0.8<r_{\mathrm{xcor}}<0.9\right)$, stable $\mathrm{SW}$ winds $\left(\mathrm{dd}_{\mathrm{SM}}=228^{\circ}\right)$, moderate wind speeds (mean $\left.\mathrm{ff}_{\mathrm{SM}}=6.7 \mathrm{~m} \mathrm{~s}^{-1}\right)$, orographic cloudiness, relatively stable cloud base height of $\sim 200-250 \mathrm{~m}$ with an increasing LWC of $\sim 0.1-0.3 \mathrm{~g} \mathrm{~m}^{-3}$, no precipitation, quite stable thermal stratification, slightly decelerated flow possible at the end of the FCE (slight LUV blocking, $F r=1.4$ and increasing CODs), slightly changing trajectories and air mass advection, relatively short duration ( $3 \mathrm{~h} 40 \mathrm{~min}$ ), conditions during the offline sampling period not as adequate as at the beginning of the FCE, suitable overflow conditions predicted by the COSMO model

$\rightarrow$ Suitable FCE: adequate meteorological/connected flow conditions
\end{abstract}

\section{FCE11.2}

01-10-2010 20:50

to $02-10-201003: 10$

(01-10-2010 22:30

to $02-10-201005: 30$ )

[Supplement section G]
Reasonable overflow conditions, with relatively high $\mathrm{COD}_{\mathrm{O}_{3}}$ values (mean $\mathrm{COD}_{\mathrm{O}_{3}, \mathrm{GL}-\mathrm{GB}} \approx 0.14$ ) and $\mathrm{COD}_{N 49 \mathrm{~nm}}$ values (mean $\mathrm{COD}_{N 49 \mathrm{~nm}, \mathrm{GL}-\mathrm{GB}} \approx 0.12$ ) and lower values just for $\mathrm{COD}_{N 49 \mathrm{~nm}, \mathrm{SM}-\mathrm{GB}}(\approx 0.06)$, which indicates a slight LUV blocking at the beginning, partially dissimilar ozone concentration profiles at the upwind site, partially high cross-correlation values, stable SW flow conditions $\left(\mathrm{dd}_{\mathrm{SM}}=222^{\circ}\right)$, weak winds $\left(\mathrm{ff}_{\mathrm{SM}}=3.7 \mathrm{~m} \mathrm{~s}^{-1}\right)$, overflow possible ( slight blocking effects, $F r=2.2$ ), very stable stratification, frontal cloudiness (occlusion front), slightly fluctuating cloud base height (100-200 m), increasing high LWC (mean $0.37 \mathrm{~g} \mathrm{~m}^{-3}$ ), no precipitation, slightly changing trajectory pattern, $6 \mathrm{~h} 20 \mathrm{~min}$ duration, conditions at the end of the offline sampling period even less adequate than during the FCE (see the COD analysis data in the Supplement), less sufficient wind field conditions predicted by the COSMO model (particularly at the beginning, where small blocking effects were predicted)

$\rightarrow$ Probably useful FCE: adequate meteorological but restricted connected flow conditions

\section{FCE11.3 \\ 02-10-2010 07:10}

to $03-10-201000: 30$

(02-10-2010

14:30-20:00)

[Supplement section $\mathrm{H}$ ]
Satisfactory overflow conditions, partially high $\mathrm{COD}$ values (mean $\mathrm{COD}_{\mathrm{O}_{3}, \mathrm{GL}-\mathrm{GB}} \approx 0.06$; mean $\left.\mathrm{COD}_{N 49 \mathrm{~nm}, \mathrm{GL}-\mathrm{GB}} \approx 0.14\right)$, with higher values mostly for the upwind site, $\operatorname{Fr}(0.8 ; 1.3)$ and $R i$ $(0.8 ; 7.2)$ numbers indicate stable stratification and the possibility of a slightly decelerated flow, higher cross-correlations during the first half of the FCE than during the second, stable SW flow conditions $\left(\mathrm{dd}_{\mathrm{SM}}=220^{\circ}\right)$, moderate to high wind speeds (mean $\left.\mathrm{ff}_{\mathrm{SM}}=6.3 \mathrm{~m} \mathrm{~s}^{-1}, 3.6-9.2 \mathrm{~m} \mathrm{~s}^{-1}\right)$, slight precipitation $\left(\mathrm{RR}_{\mathrm{SM}} \approx 0.5 \mathrm{~mm}\right.$ ) particularly in the first half of the FCE, frontal cloudiness (associated with a warm front), variable cloud height $(100-300 \mathrm{~m})$, partially high LWC values (mean $0.32 \mathrm{~g} \mathrm{~m}^{-3}$ ), stable trajectory pattern, long duration $(17 \mathrm{~h} 20 \mathrm{~min})$, mostly good overflow conditions predicted by the COSMO model (small upwind deceleration of the flow predicted from 20:00 onward)

$\rightarrow$ Suitable FCE: adequate meteorological/ connected flow conditions

\section{FCE13.3 \\ 06-10-2010 06:50}

to $07-10-201001: 00$

(06.10-2010 12:15

to $07-10-201003: 15)$

[Supplement section I]
Reasonably good overflow conditions, partially high $\mathrm{COD}$ values (mean $\mathrm{COD}_{\mathrm{O}_{3}, \mathrm{GL}-\mathrm{GB}} \approx 0.07$; mean $\left.\mathrm{COD}_{N 49 \mathrm{~nm}, \mathrm{GL}-\mathrm{GB}} \approx 0.15\right), \operatorname{Fr}(0.85 ; 1.2)$ and $R i(3.2 ; 1.7)$ numbers indicate stable stratification and the possibility of a slightly decelerated flow, upwind site $\mathrm{O}_{3}$ concentration profiles partially dissimilar, higher cross-correlations during the first half of the FCE than during the second (overall $\left.r_{\text {xcor }}>0.8\right)$, stable SW flow conditions $\left(\mathrm{dd}_{\mathrm{SM}}=223^{\circ}\right)$ with weak wind speeds ( $\mathrm{ff}_{\mathrm{SM}}=4.2 \mathrm{~m} \mathrm{~s}^{-1}$ ), orographic cloudiness, relative stable cloud base height (100-200 m), high LWC values (mean $0.32 \mathrm{~g} \mathrm{~m}^{-3}$, $\left.\mathrm{LWC}_{\max }=0.58 \mathrm{~g} \mathrm{~m}^{-3}\right)$, no precipitation, unstable trajectories, long duration $(15 \mathrm{~h})$, inadequate flow conditions at the end of the offline sampling event (see the COD analysis in the Supplement), acceptable overflow conditions predicted by the COSMO model (upwind deceleration of the flow predicted from 20:00 onward)

$\rightarrow$ Suitable FCE: partially adequate meteorological/ connected flow conditions

\section{FCE22.0}

19-10-2010 01:50

to $19-10-201009: 00$

(no offline sampling) [Supplement section J]
Mostly good overflow conditions, relatively low $\mathrm{COD}_{\mathrm{O}_{3}}$ values (mean $\mathrm{COD}_{\mathrm{O}_{3}}$, GL-GB $<0.03$ ), $\mathrm{COD}_{N 49 \mathrm{~nm}}$ (mean $\mathrm{COD}_{N 49 \mathrm{~nm}, \mathrm{GL}-\mathrm{GB}}<0.12$ ), congruent $\mathrm{O}_{3}$ concentrations, very high crosscorrelations $\left(r_{\mathrm{xcor}}>0.9\right)$, stable thermal stratification, slightly decelerated flow possible at the start of the FCE only $(F r=1.1)$, stable SW winds (mean $\left.\mathrm{dd}_{\mathrm{SM}}=233^{\circ}\right)$, moderate wind speeds (mean $\left.\mathrm{ff}_{\mathrm{SM}}=5.1 \mathrm{~m} \mathrm{~s}^{-1}\right)$, relatively stable cloud base height $(100-200 \mathrm{~m})$, moderate LWC values $(0.2-$ $0.4 \mathrm{~g} \mathrm{~m}^{-3}$ ), temperature below $273 \mathrm{~K}$, low clouds and slight precipitation at the end of the FCE due to an occlusion, good overflow conditions predicted by the COSMO model for the second half of the FCE (small blocking of the upwind flow/downdrafts during the first half possible)

$\rightarrow$ Partially suitable FCE: adequate meteorological and partially restricted connected flow conditions 
Table 5. Continued.

\begin{tabular}{|c|c|}
\hline $\begin{array}{l}\text { (19-1 } \\
\text { to } 20 \\
\text { [Sup }\end{array}$ & $\begin{array}{l}\text { Acceptable overflow conditions, reasonable } \mathrm{COD}_{\mathrm{O}_{3}} \text { values (mean } \mathrm{COD}_{\mathrm{O}_{3}, \mathrm{GL}-\mathrm{GB}}=0.09 \text { ), } \\
\left.\mathrm{COD}_{N 49 \mathrm{~nm}} \text { (mean } \mathrm{COD}_{N 49 \mathrm{~nm}, \mathrm{GL}-\mathrm{GB}}=0.09\right) \text {, less congruent } \mathrm{O}_{3} \text { concentrations, reasonable cross- } \\
\text { correlations, stable thermal stratification, slightly decelerated flow possible at the end of the FCE } \\
\left.(\mathrm{Fr}=1.2) \text {, WSW to W flow conditions (mean } \mathrm{dd}_{\mathrm{SM}}=248^{\circ}\right) \text {, low/moderate wind speed (mean } \\
\left.\mathrm{ff}_{\mathrm{SM}}=4.7 \mathrm{~m} \mathrm{~s}^{-1}\right) \text {, varying cloud height }(100-200 \mathrm{~m}) \text {, almost constant } \mathrm{LWC} \text { (mean } 0.31 \mathrm{~g} \mathrm{~m}^{-3} \text { ), pre- } \\
\text { cipitation }\left(\mathrm{RR}_{\mathrm{SM}}<0.2 \mathrm{~mm}\right) \text {, reasonably stable trajectories, long duration }(5 \mathrm{~h} 20 \mathrm{~min}) \text {, flow conditions } \\
\text { still adequate at the end of the offline sampling event (see the COD analysis in the Supplement) but } \\
\text { precipitation at all sites, stable SW winds with a small blocking of the upwind flow predicted by the } \\
\text { COSMO model } \\
\rightarrow \text { Suitable FCE: adequate meteorological/ connected flow conditions }\end{array}$ \\
\hline $\begin{array}{l}\text { FCE24.0 } \\
21-10-20 \\
\text { to } 22-10\end{array}$ & 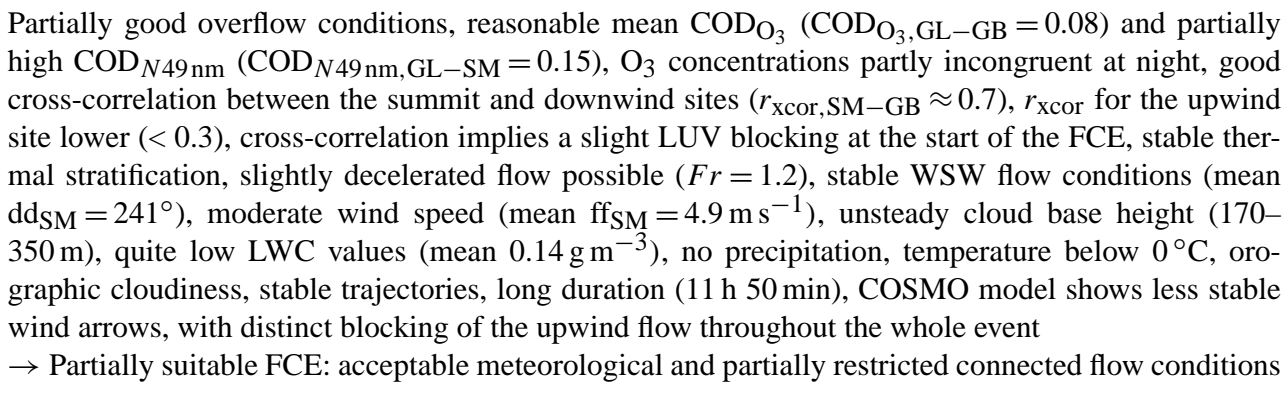 \\
\hline $\begin{array}{l}0 \\
15)\end{array}$ & $\begin{array}{l}\text { Good overflow conditions, with low } \mathrm{COD}_{\mathrm{O}_{3}}\left(\mathrm{COD}_{\mathrm{O}_{3}, \mathrm{GL}-\mathrm{GB}}=0.01\right) \text { and } \mathrm{COD}_{N 49 \mathrm{~nm}} \\
(\mathrm{COD} N 49 \mathrm{~nm}<0.1) \text { values, congruent } \mathrm{O}_{3} \text { concentration profiles, high overall cross-correlations } \\
\left(0.7<r_{\mathrm{Xcor}}<0.9\right) \text {, low } F r \text { number }(F r=0.42) \text {, stable stratification, stable } \mathrm{SW} \text { flow conditions (mean } \\
\left.\left.\mathrm{dd}_{\mathrm{SM}}=233^{\circ}\right) \text {, high wind speed (mean } \mathrm{ff}_{\mathrm{SM}}=9.7 \mathrm{~m} \mathrm{~s}^{-1}\right) \text {, inconsistent trajectories, post-frontal } \\
\text { clouds (probably not purely orographic), relatively stable } \mathrm{LWC}\left(\text { mean } 0.19 \mathrm{~g} \mathrm{~m}^{-3}\right) \text {, variable cloud } \\
\text { base height }(300-130 \mathrm{~m}) \text {, light precipitation during the } \mathrm{FCE}\left(\mathrm{RR}_{\mathrm{SM}}<0.8 \mathrm{~mm}\right), 7.5 \mathrm{~h} \text { duration, flow } \\
\text { conditions still adequate at the end of the offline sampling event (see COD analysis in the Supplement) } \\
\text { but precipitation at all sites, suitable overflow conditions predicted by the COSMO model } \\
\rightarrow \text { Suitable FCE with adequate meteorological/ connected flow conditions }\end{array}$ \\
\hline $\begin{array}{l}\text { (24-10 } \\
09: 15 \\
\text { [Supp }\end{array}$ & $\begin{array}{l}\text { Mostly good overflow conditions, low } \mathrm{COD}_{\mathrm{O}_{3}}\left(\mathrm{COD}_{\mathrm{O}_{3}, \mathrm{GL}-\mathrm{GB}}=0.01\right) \text { but rather high } \mathrm{COD}_{N 49 \mathrm{~nm}} \\
\left(\mathrm{COD}_{N 49 \mathrm{~nm}, \mathrm{GL}-\mathrm{GB}}=0.23\right) \text {, congruent } \mathrm{O}_{3} \text { concentration profiles, good cross-correlations } \\
\left.\left(0.65<r_{\mathrm{xcor}}<0.85\right) \text {, low } \mathrm{Fr} \text { number, } \mathrm{SW} / \mathrm{WSW} \text { flow conditions (mean dd } \mathrm{SM}=239^{\circ}\right) \text {, high } \\
\left.\text { wind speed (mean } \mathrm{ff}_{\mathrm{SM}}=9.0 \mathrm{~m} \mathrm{~s}^{-1}\right) \text {, inconsistent trajectories, post-frontal cloudiness and precipi- } \\
\text { tation }\left(\mathrm{RR}_{\mathrm{SM}}<0.4 \mathrm{~mm}\right) \text {, cloud base height } \sim 200 \mathrm{~m} \text {, increasing above } 350 \mathrm{~m} \text { at the end of the FCE, } \\
\left.\text { decreasing LWC (mean } 0.15 \mathrm{~g} \mathrm{~m}^{-3}\right), 3 \mathrm{~h} 40 \mathrm{~min} \text { duration, suitable overflow conditions predicted by } \\
\text { the COSMO model } \\
\rightarrow \text { Suitable FCE, but short event, with adequate meteorological and most likely adequate connected } \\
\text { flow conditions }\end{array}$ \\
\hline
\end{tabular}

modelled results are quite consistent with the results obtained from the COD and cross-correlation analyses discussed previously. Therefore, the connected flow validation scheme developed in this work is approved to be applicable for identifying suitable flow conditions for a hill cap cloud experiment.

\subsection{Tracer experiments}

Four $\mathrm{SF}_{6}$ tracer experiments (TEs) were carried out during the HCCT-2010 campaign (TE1-TE4; see Table 1). Although all of these experiments were carried out when local meteorological conditions seemed favourable, postcampaign COD analysis of flow connectivity between the three measurement sites revealed that only two of the experi- ments (TE1 and TE3; see Supplement) were conducted under connected flow conditions suitable for Lagrangian-type comparisons of concentrations at upwind and downwind sites. TE1 was conducted during the NCE0.4 period, while TE3 was conducted during the FCE13.3 period. By contrast, COD analysis indicated that the other two experiments (TE2 and TE4) were performed under conditions of poor flow connectivity between the sites. For this reason, only the results obtained during TE1 and TE3 are shown in Fig. 8.

Different plume pathways were observed during TE1 and TE3, which reflects differences in the dominant wind direction during these experiments. The mean wind direction at the Mt. Schmücke summit site $\left(\operatorname{dd}_{S M}, 20\right)$ had a higher westerly component during TE1 (mean $\mathrm{dd}_{\mathrm{SM}}$ of $240^{\circ}$, 


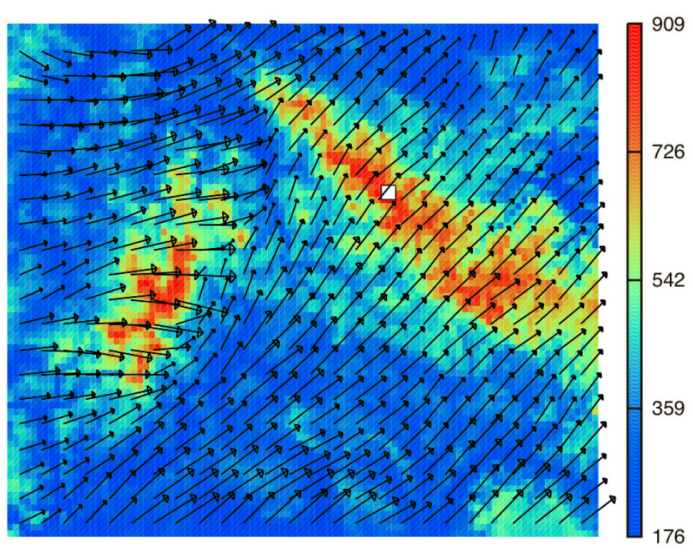

24. Sep $201021: 00$

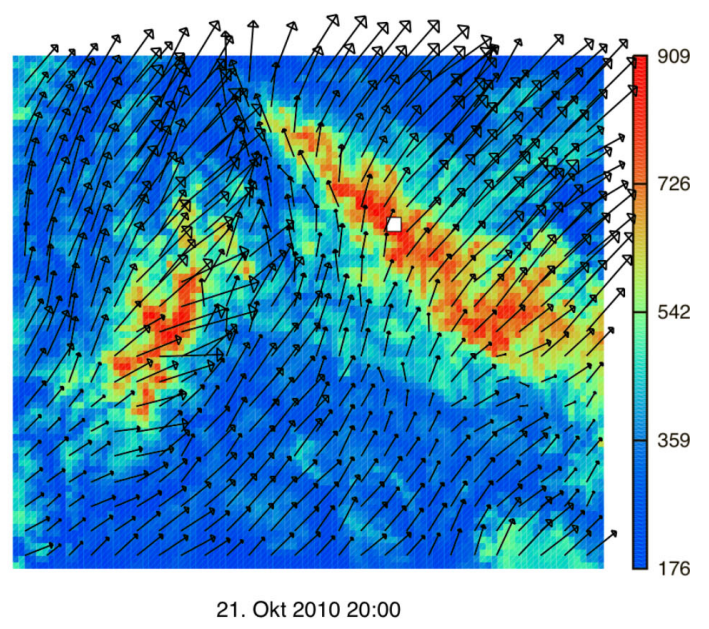

Figure 7. Depiction of the horizontal cross-section of the topography and the wind conditions (black arrows) above the ground for the COSMO model domain at 21:00 UTC on 24 September 2010 (left graphic) and at 20:00 UTC on 21 October 2010 (right graphic). The white square represents the Mt. Schmücke site.

see Table 1) than during TE3 (mean $\mathrm{dd}_{\mathrm{SM}}$ of $220^{\circ}$ ). As a result, the TE1 plume passed closer to the sampling sites to the east of the release site $(22,44$, and 32$)$ than those to the west of the release site $(21,41$, and 30$)$. The opposite was observed during TE3: higher $\mathrm{SF}_{6}$ mixing ratios were observed at the western sites (41 and 30). Although somewhat lower $\mathrm{SF}_{6}$ mixing ratios were observed at the western site 21 than at its eastern counterpart site 22, peak $\mathrm{SF}_{6}$ concentrations at site 22 were reached later than at the Mt. Schmücke site (20), which is further downwind. This indicates that site 22 was likely not part of the main pathway of the plume.

During both TE1 and TE3, the highest $\mathrm{SF}_{6}$ mixing ratios $(\sim 110 \mathrm{ppt})$ were usually observed at the Mt. Schmücke site. As a result of diffusion and dilution, lower mixing ratios were observed at the downwind sites. However, $\mathrm{SF}_{6}$ concentrations at these sites (30-60 ppt) were still well above background levels, which provides support for the assumption that connected air flow between the upwind, summit and downwind sites was present during these experiments.

Although the $\mathrm{SF}_{6}$ plume did not directly pass the Gehlberg downwind site (30) during TE3, it did, however, pass the nearby Am Brand downwind site (32). It seems valid, therefore, to assume that during the FCEs (and NCEs), where a spatially more homogeneous aerosol population was transported through the area (i.e. rather than a plume originating from a point source), representative air parcels were able to be sampled at the Gehlberg site (30), as long as a SW flow was present.

The $\mathrm{SF}_{6}$ transit time - here defined as the time difference between its initial release and the measurement of the maximum mixing ratio at one of the two downwind sites (30 or 32) - was $30 \mathrm{~min}$ for TE1 and $45 \mathrm{~min}$ for TE3. The mean wind speed at the Schmücke site during TE1 was about twice as high as that measured during TE3, which provides qualita- tive support for the faster transit time observed during TE1. It should be noted that in both experiments the measured transit time also included the time required for $\mathrm{SF}_{6}$ to diffuse from the ground to higher altitudes, where it then could be transported with higher wind speeds. Since the upwind site is located close to the ground and in a rather narrow valley, the wind speed at this location was always significantly lower than at Mt. Schmücke $\left(<1 \mathrm{~m} \mathrm{~s}^{-1}\right.$ during both TE1 and TE3). The transit times observed during the $\mathrm{SF}_{6}$ tracer experiments are thus expected to be somewhat longer than those of "representative" air parcels during FCEs, since these parcels did not arise from a point source on the ground but rather travelled with the higher wind speeds above the ground.

Experimental results for the TE2 and TE4 tracer experiments are shown in Figs. S5 and S6 in the Supplement. Much lower $\mathrm{SF}_{6}$ mixing ratios were observed at the Mt. Schmücke summit (20) and at the downwind sites 30 and 32 during TE2 than during TE1 and TE3, which indicates either that the $\mathrm{SF}_{6}$ plume did indeed not directly pass these sites or that vertical lifting from the upwind site was blocked. During TE4, no increase in $\mathrm{SF}_{6}$ mixing ratios was observed for the first 40 min after the initial $\mathrm{SF}_{6}$ release, even at the sites closest to the upwind site (21 and 22), which indicates a strong decoupling/blocking of the upwind site. This finding is supported by the flow connectivity analysis performed for this time period (see the Supplement). Together, these results confirm that flow connectivity between the measurement sites was not present during TE2 and TE4.

Overall, the $\mathrm{SF}_{6}$ tracer experiments serve as empirical support for two crucial assumptions/prerequisites of the HCCT2010 campaign: (i) under appropriate meteorological conditions a Lagrangian-type analysis of experimental data is valid and (ii) the flow validation scheme developed in this work is suitable for identifying such conditions. 

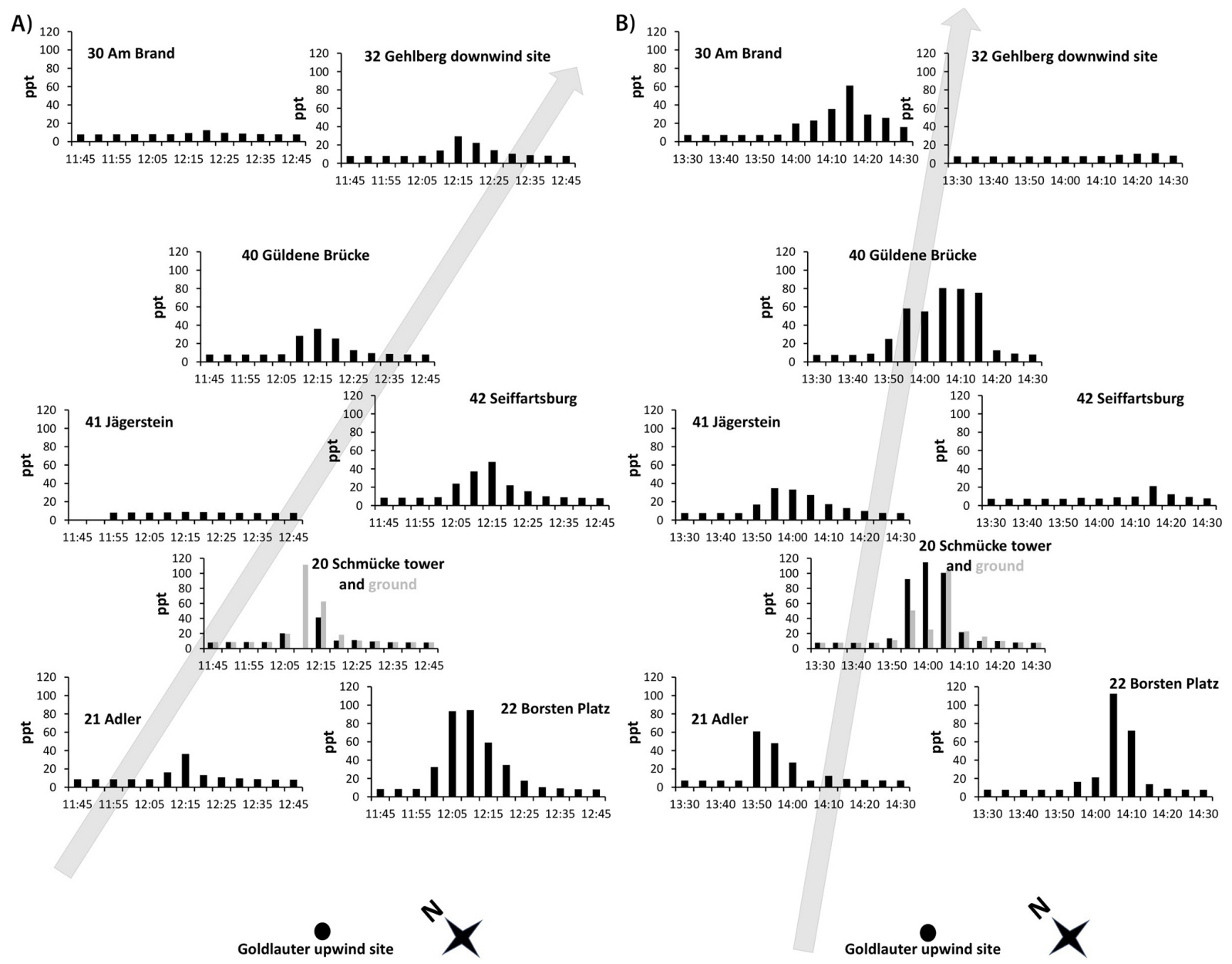

Figure 8. $\mathrm{SF}_{6}$ mixing ratios at measurement sites during the (a) TE1 and (b) TE3 tracer experiments. The positions of the bar plots indicate the approximate geographic positions of the sites, and the grey arrow on each plot indicates the mean wind direction at the Mt. Schmücke summit site during the experiments. $\mathrm{SF}_{6}$ release was conducted at the upwind site Goldlauter.

\subsection{Overall evaluation of the FCEs}

A comprehensive assessment of the meteorological and flow conditions during the ground-based cloud passage campaign HCCT-2010 has been used to conclusively verify that the selected FCEs meet the required conditions for a Lagrangiantype experiment. The results of this assessment, including the advantages and disadvantages of each individual FCE, are outlined in Table 5. This table also includes an overall conclusive statement regarding the suitability of the meteorological and flow connectivity conditions during each FCE.

It can be qualitatively concluded from Table 5 that the meteorological and flow connectivity conditions during the 14 FCEs largely fulfilled the requirements associated with the Lagrangian-type experiment performed during HCCT2010. Since each FCE has unique advantages and disadvantages, however, no final ranking of the FCEs was performed. Furthermore, it is necessary to keep disadvantages of some FCEs, such as occurred precipitation, in mind. Some disad- vantages might be needed for further investigations and interpretations of other measurement data. Despite these disadvantages, however, all FCEs and NCEs identified in the present study are recommended for use in further investigations of the HCCT-2010 data set.

\section{Summary}

The main goal of the present study was to provide a comprehensive evaluation of the meteorological and connected flow conditions present during the ground-based Lagrangian-type experiment HCCT-2010, in order to provide a set of suitable measurement time periods for detailed investigations (see e.g. Harris et al., 2013, 2014; Spiegel et al., 2012). In order to accomplish this goal, synoptic- and local-scale advection conditions during HCCT-2010 were examined and classified. The local flow conditions throughout the entire measurement period were studied by means of statistical analyses and corresponding statistical measures (COD and cross-correlation). 
In particular, the particle number concentrations in specific aerosol size bins and the concentrations of the quasi-inert trace gas ozone at the upwind, summit and downwind sites were used for the statistical analyses.

The entire HCCT-2010 measurement period was analysed with respect to flow connectivity between the three measurement sites and the presence or non-presence of a cloud at the sites. For further verification of the local flow connectivity and improved understanding of local air transport processes in the experimental area, tracer experiments were conducted using the inert gas $\mathrm{SF}_{6}$. Then, full-cloud events (FCEs) and non-cloud events (NCEs) were identified in an objective manner according to a set of developed flow and precipitation criteria. The mesoscale airflow over the mountain ridge during the identified FCEs and NCEs was characterised by means of the non-dimensional parameters $\mathrm{Fr}$ and $R i$, which were calculated from rawinsonde observation data. In addition, the local meteorological conditions during the identified FCEs were studied in detail. Simulations performed using the weather forecast model COSMO were used to further investigate the regional and local flow conditions. These simulations enabled the characterisation of the regional wind pattern and the identification of decelerated or blocked flow conditions at the upwind site and downdrafts at the downwind site.

This comprehensive examination showed that orographic cloudiness was most often observed for SW weather type situations with stable incoming flow. In total, approximately one third of the examined HCCT-2010 cloud periods were characterised by orographic cloudiness; the other two thirds were characterised by clouds associated with synoptic fronts. The results of the statistical flow analyses and $\mathrm{SF}_{6}$ tracer experiments performed in this study show that a strong link between the three measurement sites exists, particularly under constant SW flow, high wind speed and slightly stable stratification conditions. The findings of the COD and crosscorrelation analysis were supported by results obtained from regional modelling. The overall evaluation of the HCCT2010 measurement period with respect to meteorological and connected flow conditions resulted in the identification of 14 FCEs useful for further studies (see http://www. atmos-chem-phys.net/special_issue287.html).

In conclusion, the present study used an unprecedentedly comprehensive variety of tools, including tracer experiments, statistical measures, non-dimensional flow parameters and regional modelling, to provide a comprehensive analysis of connected flow conditions crucial for a Lagrangian-type hill cap cloud experiment. Results obtained using the statistical approach and those obtained using the experimental and modelling approach exhibited a high degree of consistency. This is a significant result suggesting that statistical tools such as cross-correlation and COD analysis can be applied in future Lagrangian-type studies with greater confidence than before. Overall, the results of the present paper demonstrate that, under appropriate meteorological conditions, a
Lagrangian-type approach is valid for hill cap cloud experiments. Finally, the methods and tools developed and applied in the present study can be used for the identification of suitable meteorological and connected airflow conditions during future Lagrangian-type hill cap cloud experiments.

\section{The Supplement related to this article is available online at doi:10.5194/acp-14-9105-2014-supplement.}

Acknowledgements. This work was supported by the German Research Foundation (DFG, He 3086/15-1, DFG grant Me 3534/1-2).

Edited by: C. George

\section{References}

Baines, P. G.: Topographic Effects in Stratified Flows, Cambridge University Press, Cambridge, 1995.

Baldauf, M., Seifert, A., Forstner, J., Majewski, D., Raschendorfer, M., Reinhardt, T.: Operational convective-scale numerical weather prediction with the COSMO model: Description and sensitivities, Mon. Weather Rev., 139, 3887-3905, 2011.

Boucher, O., Randall, D., Artaxo, P., Bretherton, C., Feingold, G., Forster, P., Kerminen, V.-M., Kondo, Y., Liao, H., Lohmann, U., Rasch, P., Satheesh, S. K., Sherwood, S., Stevens, B., and Zhang, X. Y.: Clouds and Aerosols, in: Climate Change 2013: The Physical Science Basis. Contribution of Working Group I to the Fifth Assessment Report of the Intergovernmental Panel on Climate Change, edited by: Stocker, T. F., Qin, D., Plattner, G.-K., Tignor, M., Allen, S. K., Boschung, J., Nauels, A., Xia, Y., Bex, V., and Midgley, P. M., Cambridge University Press, Cambridge, United Kingdom and New York, NY, USA, 571-657, 2013.

Bower, B. K. N., Choularton, T. W., Gallagher, M. W., Beswick, K. M., Flynn, M. J., Allen, A. G., Davison, B. M., James, J. D., Robertson, L., Harrison, R. M., Hewitt, C. N., Cape, J. N., McFadyen, G. G., Milford, C., Sutton, M. A., Martinsson, B. G., Frank, G., Swietlicki, E., Zhou, J., Berg, O. H., Mentes, B., Papaspiropoulos, G., Hansson, H. C., Leck, C., Kulmala, M., Aalto, P., Vakeva, M., Berner, A., Bizjak, M., Fuzzi, S., Laj, P., Facchini, M. C., Orsi, G., Ricci, L., Nielsen, M., Allan, B. J., Coe, H., McFiggans, G., Plane, J. M. C., Collett, J. L., Moore, K. F., and Sherman, D. E.: ACE-2 HILLCLOUD. An overview of the ACE-2 ground-based cloud experiment, Tellus B, 52, 750-778, 2000.

Bower, K. N., Choularton, T. W., Gallagher, M. W., Colvile, R. N., Beswick, K. M., Inglis, D. W. F., Bradbury, C., Martinsson, B. G., Swietlicki, E., Berg, O. H., Cederfelt, S. I., Frank, G., Zhou, J., Cape, J. N., Sutton, M. A., McFadyen, G. G., Milford, C., Birmili, W., Yuskiewicz, B. A., Wiedensohler, A., Stratmann, F., Wendisch, M., Berner, A., Ctyroky, P., Galambos, Z., Mesfin, S. H., Dusek, U., Dore, C. J., Lee, D. S., Pepler, S. A., Bizjak, M., and Divjak, B.: The Great Dun Fell Experiment 1995: an overview, Atmos. Res., 50, 151-184, 1999.

Bruintjes, R. T., Clark, T. L., and Hall, W. D.: The Dispersion of Tracer Plumes in Mountainous Regions in Central Arizona 
- Comparisons between Observations and Modeling Results, J. Appl. Meteorol., 34, 971-988, 1995.

Choularton, T. W., Colvile, R. N., Bower, K. N., Gallagher, M. W., Wells, M., Beswick, K. M., Arends, B. G., Mols, J. J., Kos, G. P. A., Fuzzi, S., Lind, J. A., Orsi, G., Facchini, M. C., Laj, P., Gieray, R., Wieser, P., Engelhardt, T., Berner, A., Kruisz, C., Moller, D., Acker, K., Wieprecht, W., Luttke, J., Levsen, K., Bizjak, M., Hansson, H. C., Cederfelt, S. I., Frank, G., Mentes, B., Martinsson, B., Orsini, D., Svenningsson, B., Swietlicki, E., Wiedensohler, A., Noone, K. J., Pahl, S., Winkler, P., Seyffer, E., Helas, G., Jaeschke, W., Georgii, H. W., Wobrock, W., Preiss, M., Maser, R., Schell, D., Dollard, G., Jones, B., Davies, T., Sedlak, D. L., David, M. M., Wendisch, M., Cape, J. N., Hargreaves, K. J., Sutton, M. A., StoretonWest, R. L., Fowler, D., Hallberg, A., Harrison, R. M., and Peak, J. D.: The Great Dun Fell Cloud Experiment 1993: An overview, Atmos. Environ., 31, 2393-2405, 1997.

Colle, B. A.: Sensitivity of orographic precipitation to changing ambient conditions and terrain geometries: An idealized modeling perspective, J. Atmos. Sci., 61, 588-606, 2004.

Colvile, R. N., Bower, K. N., Choularton, T. W., Gallagher, M. W., Wobrock, W., Hargreaves, K. J., Storeton-West, R. L., Cape, J. N., Jones, B., Wiedensohler, A., Hansson, H.-C., Wendisch, M., Acker, K., Wieprecht, W., Pahl, S., Winkler, P., Berner, A., and Kruisz, C.: Meteorology of the Great Dun Fell Cloud Experiment 1993, Atmos. Environ., 31, 2407-2420, 1997.

Draxler, R. and Rolph, G.: HYSPLIT (HYbrid Single-Particle Lagrangian Integrated Trajectory) Model access via NOAA ARL READY, NOAA Air Resources Laboratory, Silver Spring, MD, 2003.

Harris, E., Sinha, B., van Pinxteren, D., Schneider, J., Poulain, L., Collett, J., D’Anna, B., Fahlbusch, B., Foley, S., Fomba, K. W., George, C., Gnauk, T., Henning, S., Lee, T., Mertes, S., Roth, A., Stratmann, F., Borrmann, S., Hoppe, P., and Herrmann, H.: In-cloud sulfate addition to single particles resolved with sulfur isotope analysis during HCCT-2010, Atmos. Chem. Phys., 14, 4219-4235, doi:10.5194/acp-14-4219-2014, 2014.

Harris, E., Sinha, B., van Pinxteren, D., Tilgner, A., Fomba, K. W., Schneider, J., Roth, A., Gnauk, T., Fahlbusch, B., Mertes, S., Lee, T., Collett, J., Foley, S., Borrmann, S., Hoppe, P., and Herrmann, H.: Enhanced Role of Transition Metal Ion Catalysis During InCloud Oxidation of $\mathrm{SO}_{2}$, Science, 10, 727-730, 2013.

Heinold, B., Tilgner, A., Jaeschke, W., Haunold, W., Knoth, O., Wolke, R., and Herrmann, H.: Meteorological characterisation of the FEBUKO hill cap cloud experiments, Part II: Tracer experiments and flow characterisation with nested non-hydrostatic atmospheric models, Atmos. Environ., 39, 4195-4207, 2005.

Heintzenberg, J. and Charlson, R. J.: Clouds in the perturbed climate system: Their relationship to energy balance, atmospheric dynamics, and precipitation, MIT Press, Cambridge, MA, USA, 57 pp., 2009.

Herrmann, H., Wolke, R., Müller, K., Brüggemann, E., Gnauk, T., Barzaghi, P., Mertes, S., Lehmann, K., Massling, A., Birmili, W., Wiedensohler, A., Wieprecht, W., Acker, K., Jaeschke, W., Kramberger, H., Svrcina, B., Bächmann, K., Collett, J. L. J., Galgon, D., Schwirn, K., Nowak, A., Pinxteren, D. v., Plewka, A., Chemnitzer, R., Rüd, C., Hofmann, D., Tilgner, A., Diehl, K., Heinold, B., Hinneburg, D., Knoth, O., Sehili, A. M., Simmel, M., Wurzler, S., Majdik, Z., Mauersberger, G., and Müller,
F.: FEBUKO and MODMEP: Field measurements and modelling of aerosol and cloud multiphase processes, Atmos. Environ., 39, 4169-4183, 2005.

Jarvis, A., Reuter, H. I., Nelson, A., Guevara, E.: Hole-filled SRTM for the globe Version 4, available from the CGIAR-CSI SRTM 90m Database, available at: http://srtm.csi.cgiar.org (last access: 18 June 2014), 2008.

Jiang, Q. F.: Moist dynamics and orographic precipitation, Tellus A, 55, 301-316, 2003.

Krudysz, M. A., Froines, J. R., Fine, P. M., and Sioutas, C.: Intracommunity spatial variation of size-fractionated PM mass, OC, $\mathrm{EC}$, and trace elements in the Long Beach, CA area, Atmos. Environ., 42, 5374-5389, 2008.

Möller, D.: Chemistry of the Climate System, Walter de Gruyter, Berlin, 722 pp., 2010.

Ott, D. K., Kumar, N., and Peters, T. M.: Passive sampling to capture spatial variability in $\mathrm{PM}_{10-2.5}$, Atmos. Environ., 42, 746-756, 2008.

Pierrehumbert, R. T. and Wyman, B.: Upstream Effects of Mesoscale Mountains, J. Atmos. Sci., 42, 977-1003, 1985.

Pinto, J. P., Lefohn, A. S., and Shadwick, D. S.: Spatial variability of $\mathrm{PM}_{2.5}$ in urban areas in the United States, J. Air Waste Manage., 54, 440-449, 2004.

Pruppacher, H. R. and Jaenicke, R.: The Processing of Water-Vapor and Aerosols by Atmospheric Clouds, a Global Estimate, Atmos. Res., 38, 283-295, 1995.

Ravishankara, A. R.: Heterogeneous and multiphase chemistry in the troposphere, Science, 276, 1058-1065, 1997.

Rolph, G. D.: Real-time Environmental Applications and Display sYstem (READY) Website (http://ready.arl.noaa.gov). NOAA Air Resources Laboratory, Silver Spring, MD, 2013.

Sander, R.: Compilation of Henry's Law Constants for Inorganic and Organic Species of Potential Importance in Environmental Chemistry (Version 3), available at: http://www.henrys-law.org (last access: 15 July 2013), 1999.

Schättler, U., Doms, G., and Schraff, C.: A description of the nonhydrostatic regional COSMO-model part VII: User's GuideRep., Deutscher Wetterdienst, Offenbach. 2012.

Spiegel, J. K., Aemisegger, F., Scholl, M., Wienhold, F. G., Collett Jr., J. L., Lee, T., van Pinxteren, D., Mertes, S., Tilgner, A., Herrmann, H., Werner, R. A., Buchmann, N., and Eugster, W.: Temporal evolution of stable water isotopologues in cloud droplets in a hill cap cloud in central Europe (HCCT-2010), Atmos. Chem. Phys., 12, 11679-11694, doi:10.5194/acp-12-11679-2012, 2012.

Strunk, M., Engel, A., Schmidt, U., Volk, C. M., Wetter, T., Levin, I., and Glatzel-Mattheier, $\mathrm{H} .: \mathrm{CO}_{2}$ and SF6 as stratospheric age tracers: consistency and the effect of mesospheric SF6-loss, Geophys. Res. Lett., 27, 341-344, 2000.

Tilgner, A., Heinold, B., Nowak, A., and Herrmann, H.: Meteorological characterisation of the FEBUKO hill cap cloud experiments, Part I: Synoptic characterisation of measurement periods, Atmos. Environ., 39, 4185-4194, 2005.

USEPA: Air Quality Criteria for Particulate Matter, National Center for Environmental Assessment, Office of Research and Development, US Environmental Protection Agency, Research Triangle Park, NC 27711, Washington, DC, Report No. EPA/600/P99/002aF and EPA/600/P-99/002bF, 2004.

van Pinxteren, D., Brüggemann, E., Gnauk, T., Müller, K., Thiel, C., and Herrmann, H.: A GIS based approach to back 
trajectory analysis for the source apportionment of aerosol constituents and its first application, J. Atmos. Chem., 67, 1-28, doi:10.1007/s10874-011-9199-9, 2010.

Vosper, S. B., Mobbs, S. D., and Gardiner, B. A.: Measurements of the near-surface flow over a hill, Q. J. Roy. Meteor. Soc., 128, 2257-2280, 2002.

Wang, Y. G., Hopke, P. K., and Utell, M. J.: Urban-scale Spatialtemporal Variability of Black Carbon and Winter Residential Wood Combustion Particles, Aerosol Air Qual. Res., 11, 473481, 2011.

Wilson, K. L. and Birks, J. W.: Mechanism and elimination of a water vapor interference in the measurement of ozone by UV absorbance, Environ. Sci. Technol., 40, 6361-6367, doi:10.1021/Es052590c, 2006.
Wobrock, W., Schell, D., Maser, R., Jaeschke, W., Georgii, H. W., Wieprecht, W., Arends, B. G., Mols, J. J., Kos, G. P. A., Fuzzi, S., Facchini, M. C., Orsi, G., Berner, A., Solly, I., Kruisz, C., Svenningsson, I. B., Wiedensohler, A., Hansson, H. C., Ogren, J. A., Noone, K. J., Hallberg, A., Pahle, S., Schneider, T., Winkler, P., Winiwarter, W., Colcile, R., Choularton, T. W., Flossmann, A. I., and Borrman, S.: The Kleiner Feldberg cloud experiment 1990: An overview, J. Atmos. Chem., 19, 3-35, 1994.

Wongphatarakul, V., Friedlander, S. K., and Pinto, J. P.: A comparative study of $\mathrm{PM}_{2.5}$ ambient aerosol chemical databases, Environ. Sci. Technol., 32, 3926-3934, 1998. 